\title{
El principio de reciprocidad y sus limitaciones en la contratación pública en Colombia ${ }^{1}$
}

\section{The principle of reciprocity and its limitations in public procurement in Colombia}

Ricardo Iván Carrero Padilla*

\section{Resumen}

De conformidad con los compromisos adquiridos por Colombia en tratados internacionales y los estándares de comportamiento que ello implica, la Constitución Política de 1991 y la Ley 80 de 1993 incluyeron el principio de reciprocidad, consistente en otorgar un trato semejante al que se recibe por parte de otro sujeto sin ejercer actos discriminatorios. Es así como este principio permea la función pública y, por ende, la contratación estatal, por lo que la reciprocidad se encuentra asociada al trato nacional y no discriminatorio derivado de capítulos de compras públicas en acuerdos de libre comercio suscritos por Colombia con otros Estados, los cuales han sido objeto de examen por parte de la Corte Constitucional. De otra parte, la Ley 816 de 2003 y el Decreto 1082 de 2015 establecen la

1 Artículo de investigación.

* Abogado, egresado de la Facultad de Derecho y Ciencias Políticas de la Universidad de Ibagué; especialista en Derecho Administrativo de la Universidad de Salamanca; especialista en Derecho Comercial de la Universidad del Rosario; especialista en Derecho de la Empresa de la Universidad del Rosario; magíster en Derecho Contractual Público y Privado de la Universidad Santo Tomás. 
aplicación de condiciones especiales o criterios diferenciadores para la participación de proponentes extranjeros en procesos de selección adelantados por entidades estatales, así como para la evaluación de ofertas presentadas por extranjeros en el marco de dichos procesos. Por lo anterior, se plantea como objetivo del presente documento analizar este conflicto normativo a través de la delimitación del concepto de reciprocidad y su tratamiento legal en Colombia, a la luz del desarrollo jurisprudencial por parte de la Corte Constitucional, tanto de este principio como de los compromisos internacionales en materia de compras públicas armonizados con la carta política.

\section{Palabras clave}

Reciprocidad, Trato Nacional, Nación más favorecida, Derecho Administrativo Global, TLC, Compras públicas.

\section{Abstract}

According to the commitments acquired by Colombia in international treaties and the standards of behavior that this implies, the Political Constitution of 1991 and Law 80 of 1993 included the principle of reciprocity, consisting of granting a similar treatment to that received by another subject without exercising discriminatory acts. This is how this principle permeates the public function and, therefore, public procurement, for which reciprocity is associated with national and non-discriminatory treatment derived from public procurement chapters in free trade agreements signed by Colombia with other States, which have been subject to examination by the Constitutional Court. On the other hand, Law 816 of 2003 and Decree 1082 of 2015 establish the application of special conditions or differentiating criteria for the participation of foreign bidders in selection processes carried out by state entities, as well as for the evaluation of bids submitted by foreigners in the framework of these processes. Therefore, the objective of this document is to analyze 
this normative conflict through the delimitation of the concept of reciprocity and its legal treatment in Colombia, in light of the jurisprudential development by the Constitutional Court, both of this principle and of international commitments on public procurement harmonized with the political charter.

\section{Key words}

Reciprocity, National Treatment, Most Favored Nation, Global Administrative Law, FTA, Public Procurement.

\section{Introducción}

La Constitución Política de 1991 ha tenido en cuenta la necesidad de incluir en el ordenamiento jurídico colombiano disposiciones que propenden por la integración de los diferentes Estados, a través del respeto y el desarrollo económico. Además, se han incluido los principios de reciprocidad e igualdad que permean la función pública y, por ende, la contratación estatal. La reciprocidad hace referencia a un estándar de comportamiento entre Estados, quienes tienen concesiones mutuas entre sí. En efecto, esto genera un balance de poder, por lo que generalmente se asocia este principio a las relaciones internacionales y las políticas de comercio exterior. Debe precisarse entonces que la reciprocidad cobra mayor importancia en el ámbito de la contratación estatal con la incorporación de ciertos elementos que influyen en los procesos de compras públicas; estos aspectos son: globalización, surgimiento de un derecho administrativo global y la suscripción por parte de Colombia de diversos Tratados de Libre Comercio (TLC).

La acelerada integración de las economías por el efecto de la globalización sobrepasa las fronteras nacionales; situación en la que prevalecen los intereses económicos sobre las razones de Estado. No es sorpresa afirmar que, en este escenario, existe una tendencia de 
expansión de los mercados y sus agentes. De ahí que los compromisos internacionales, especialmente en acuerdos de comercio, implican una adecuación de los ordenamientos administrativos internos respecto al funcionamiento de los entes estatales y sus relaciones con los administrados, quienes pueden ser nacionales o extranjeros, con base en unos principios globales de buena administración. Esto constituye una garantía para que los acuerdos se apliquen adecuadamente y se cumplan los fines del Estado a través de los procesos de compras públicas.

A pesar de que la Carta Política establece de manera expresa el mandato constitucional de cumplir con los principios citados, algunas disposiciones internas, aplicables en materia de contratación estatal, se contraponen entre sí. Dicho de otra manera, la normativa aplicable vigente instaura el deber del Estado de aplicar el principio de reciprocidad en su actividad contractual, y, por otro lado, ejecuta la aplicación de condiciones diferentes para las ofertas presentadas por extranjeros frente a las ofertas nacionales. Estos procesos de selección son desarrollados por entidades públicas a través de puntajes especiales para ofertas nacionales, criterios de desempate, convocatorias limitadas a las organizaciones empresariales denominadas "mipymes" (micro, pequeña y mediana empresa) e incluso convocatorias restringidas territorialmente. Aunque la finalidad de estas disposiciones consiste en incentivar la creación de estas empresas y, asimismo, fomentar su crecimiento, no se encuentra en concordancia con los principios de reciprocidad e igualdad aplicables a dicha contratación, así como las obligaciones contraídas por el Estado colombiano en virtud de acuerdos internacionales que contienen capítulos de compras públicas.

La inclusión de la reciprocidad en la Carta Política obedece a compromisos adquiridos por parte del Estado al suscribir tratados internacionales que, a su vez, se integran en sentido lato a la legislación interna a través de una ley. La armonización de estos compro- 
misos pactados con la normativa interna aplicable se hace esencial, lo que genera obligaciones para los entes estatales sobre la base del principio de legalidad. En cierto sentido, esto garantiza la confianza de quienes se benefician de las disposiciones contenidas en acuerdos internacionales de cooperación, comercio o integración que contienen capítulos sobre compras públicas. Como se mencionó, esto resulta a través de procesos de selección desarrollados por entidades estatales bajo criterios objetivos de selección (sin discriminación alguna), en los que se ofrecen bienes y servicios. En este sentido, no se afectarían los derechos de particulares tanto extranjeros como nacionales que participan en este tipo de procesos contractuales.

Por lo anterior, una de las problemáticas que acarrea la globalización es la adecuación de normas internas a los compromisos derivados de acuerdos o tratados internacionales (de cooperación, integración, entre otros) que contengan disposiciones o capítulos sobre compras públicas. Habría que preguntarse entonces si el marco normativo existente y aplicable a la contratación estatal, en cuanto a incentivos y apoyo a la industria nacional, es adecuado para abordar estas disposiciones. Se evidencia una discordancia cuando normas de jerarquía superior establecen que debe existir una correspondencia de derechos y obligaciones entre los Estados que han suscrito un acuerdo (iguales entre sí) y, asimismo, través de normas internas se restringe esa correspondencia, como sucede con el apoyo a la industria nacional y los incentivos comentados. En Colombia, actualmente, los poderes legislativo y ejecutivo no han tenido en cuenta la realidad sobre los compromisos adquiridos en el marco de acuerdos internacionales que tienen una aplicación directa sobre el derecho contractual público interno.

De acuerdo con los lineamientos constitucionales y los tratados de cooperación suscritos con miras a la integración regional, el principio de reciprocidad en materia de contratación no debe encontrar obstáculo alguno para su desarrollo en la legislación interna. Debe 
quedar claro que bajo las disposiciones que fomentan el desarrollo de la industria nacional, no puede restársele valor a las propuestas realizadas por oferentes extranjeros si cumplen con todas las condiciones jurídicas, financieras, económicas y técnicas que requiere la administración. Lo anterior, puesto que, si se realiza una selección objetiva, estos pueden ser mejores que las propias de los nacionales, garantizando la satisfacción de las necesidades de la administración. De aplicar este tipo de disposiciones, el legislador y el ejecutivo crean una "excepción", contraviniendo lo establecido en la Carta Política y acuerdos internacionales en materia de reciprocidad.

Como es bien sabido, Colombia es un Estado que se encuentra en constante producción normativa. Por lo mismo, con la fijación de unos criterios que permitan facilitar la reciprocidad aplicable a procesos estatales de contratación, se beneficiaría no solamente el país de origen, sino los demás miembros de la comunidad internacional. Esto resulta una ventaja, puesto que facilitaría los fines del Estado y, asimismo, permitiría un desarrollo más fluido de la economía, la cual debe tener como base el respeto a los principios internacionales, estándares de conducta y la satisfacción del interés general. De ahí que sea indispensable que el ordenamiento interno se oriente teniendo en cuenta los principios y lineamientos contenidos en los artículos 9, 209, 226 y 227 de la Constitución Política de Colombia.

\section{El principio de reciprocidad}

El contrato estatal es una de las herramientas más eficaces con que cuentan los Estados para alcanzar los fines determinados por su Constitución. El funcionamiento de las entidades estatales y el cumplimiento de las funciones asignadas por la Constitución y la ley dependen del aprovisionamiento de bienes y servicios, lo cual se logra a través de la actividad contractual. En el plano de la contratación pública, los Estados contemplan como objetivo enfocar su poder de compra como un instrumento de intervención en el mercado, bus- 
cando resultados en términos de política económica y social; además, teniendo en cuenta que el volumen de esta contratación supera un porcentaje no despreciable de su Producto Interno Bruto (PIB) (Suárez, 2009). Los Estados, al igual que los operadores privados, son agentes que intervienen en las relaciones económicas, puesto que participan en las transacciones que se realizan en los mercados de bienes, servicios y capitales. Por lo que la aplicación del principio de reciprocidad en materia de comercio necesariamente se extiende a la contratación estatal en Colombia, como se expone más adelante.

Naturalmente, la globalización económica a menudo se contrapone a la normativa interna de los Estados, pero, a su vez, crea derechos. Conviene distinguir que estos derechos no solo le conciernen a la esfera privada, por ejemplo, la eliminación de barreras al comercio para efectos de vender en mercados abiertos, sino también a la esfera pública, como es la regulación de relaciones entre instancias gubernamentales y organizaciones globales o de materias específicas y el orden legal global (Cassese, 2005). La noción de soberanía económica, entendida como aquella potestad del Estado de determinar los modelos a implementar en ese plano, ha evolucionado con la globalización al aumentar cuantitativa y cualitativamente los límites del Estado en el ejercicio de sus derechos soberanos. Se puede afirmar que la creación y regulación de una política económica ya no depende exclusivamente del Estado.

En definitiva, la globalización tiene un efecto sobre los Estados, debido a que reduce gradualmente su capacidad de decisión sobre sus legislaciones internas (Rojas, 2011) y, en especial, sobre los mecanismos tradicionales de Derecho Internacional, que regulan la acción colectiva de la comunidad internacional. De forma tradicional, las normas internacionales provienen de tratados internacionales, constitutivos de acuerdos obligatorios entre Estados, los cuales son instrumentos normativos importantes para el desarrollo de la cooperación. Cabe aclarar que dichos procesos originan la necesidad de ar- 
monizar las reglas de derecho de los Estados que son parte de los tratados internacionales para que la fuente normativa pueda ejecutarse materialmente y, al mismo tiempo, sea vinculante. Como lo afirmó Rojas (2011), "los ordenamientos singulares (estatales) se determinan solamente con una capacidad de autodeterminación limitada a los acuerdos bilaterales o a la normativa global” (p. 305). Sin embargo, de forma paralela a los tratados, la costumbre internacional introduce reglas no codificadas aceptadas en la práctica con el paso del tiempo. Es así como el soft law ${ }^{2}$ se sitúa en un espacio intermedio de la formación del derecho que genera determinadas obligaciones jurídicas para los Estados (Pastrana, 2005). En correspondencia con esto, para que el Estado pueda ser más competente y eficaz, debe adaptarse o transformarse, complementando los mecanismos tradicionales del Derecho Internacional Público con las propuestas de particulares y de organizaciones no gubernamentales.

De acuerdo con lo mencionado, se infiere que el Derecho Internacional ha estado sufriendo una transformación, en la que son discernibles tres etapas: coordinación, cooperación y comunidad (Cassese, 2005; Ruffert y Steinecke, 2011). Mirándolo así, el Estado, según el nivel de incorporación de sus objetivos o finalidades, desarrolla estas etapas, lo cual no implica solamente la entrega de una serie de prerrogativas a organismos supranacionales, sino relaciona el empleo de mecanismos adecuados al interior de los Estados. En efecto, la idea es el desarrollo de los principios de Derecho Internacional y de una integración propiamente dicha ${ }^{3}$. La inserción de los Estados en la comunidad internacional y la suscripción de acuerdos

2 Las expectativas de conducta y preceptos que emanan de instituciones internacionales son conocidas como soft law. Sobre este concepto se puede consultar el trabajo de Feler (2015).

3 Estos principios de Derecho Internacional y de la integración son acogidos por el artículo 9 de la Constitución Política de 1991, el cual establece lo siguiente:

Las relaciones exteriores del Estado se fundamentan en la soberanía nacional, en el respeto a la autodeterminación de los pueblos y en el reconocimiento de los principios del derecho internacional aceptados por Colombia. De igual manera, la política exterior de Colombia se orientará hacia la integración latinoamericana y del Caribe. (Constitución Política de 1991, art. 9) 
de cooperación por parte de estos vuelven imperativa la aplicación de principios del derecho que se extienden a la función pública ${ }^{4} \mathrm{y}$ a la contratación administrativa ${ }^{5}$. Sin duda, lo anterior, en aras de cumplir adecuadamente con las finalidades del Estado social de derecho y desarrollar cabalmente los compromisos adquiridos, tal como lo dijo Rodríguez-Arana (2016): "[...] en el nuevo espacio jurídicoadministrativo global, funde toda su actividad en el marco de unos principios que no pueden ser otros que los del Estado de Derecho" (p. 26). Sobre esta base de principios $^{6}$, el Estado desarrolla sus actuaciones con los particulares. Así pues, la adquisición de bienes y servicios para su funcionamiento o el cumplimiento de sus fines no se encuentra exenta de su aplicación. En esta misma vía argumental, Benavides (2014) señaló lo siguiente:

La regulación de los contratos públicos está lejos de ser materia exclusiva de políticas internas de los países. Los regímenes internos no pueden tampoco entenderse sin la perspectiva internacional que los explica de manera creciente y, en todo caso, les da un trasfondo esencial para la dimensión de su alcance (Benavides, 2014, p. 65).

Existen distintos acuerdos multilaterales y bilaterales de libre comercio que regulan la contratación pública. En realidad, las impli-

4 El artículo 209 de la Constitución Política de 1991 establece lo siguiente:

La función administrativa está al servicio de los intereses generales y se desarrolla con fundamento en los principios de igualdad, moralidad, eficacia, economía, celeridad, imparcialidad y publicidad, mediante la descentralización, la delegación y la desconcentración de funciones. Las autoridades administrativas deben coordinar sus actuaciones para el adecuado cumplimiento de Ios fines del Estado. La administración pública, en todos sus órdenes, tendrá un control interno que se ejercerá en los términos que señale la ley. (Constitución Política de 1991, art. 209)

5 El artículo 23 de la Ley 80 de 1993 establece lo siguiente: Artículo 23.

De los principios en las actuaciones contractuales de las entidades estatales. Las actuaciones de quienes intervengan en la contratación estatal se desarrollarán con arreglo a los principios de transparencia, economía y responsabilidad y de conformidad con los postulados que rigen la función administrativa. Igualmente, se aplicarán en las mismas las normas que regulan la conducta de los servidores públicos, las reglas de interpretación de la contratación, los principios generales del derecho y los particulares del derecho administrativo. (Ley 80 de 1993, art. 23)

6 Para profundizar sobre los principios contractuales estatales en Colombia puede consultarse la obra de Conrado (2012). 
caciones económicas de los contratos públicos despiertan el interés de la banca multilateral, la cual ha financiado diversos proyectos de inversión. De ahí que los procesos de apertura deben tener en cuenta los intereses tanto estatales como particulares, los cuales se recogen en los citados tratados (Benavides, 2014). La protección a la inversión a través de la seguridad jurídica se torna entonces vital, vinculando de forma recíproca y sin jerarquías a estos actores en la dinámica internacional de la contratación pública.

Es así como se genera un marco de racionalidad y equilibrio que propicia un clima de confianza en el sistema de mercado, facilitando el control de la economía por parte del derecho administrativo (Rodríguez-Arana, 2016). El Estado no solo es un espectador, sino que actúa como una especie de árbitro que acompaña la economía de "forma proactiva, moderada y razonable -cuandoquiera que el juego no esté funcionando adecuadamente-, para restablecer el buen funcionamiento" (Guinard-Hernández, 2017, p. 10). Como lo aseguró Hinojosa (2010), el Estado tiene la función reguladora de esos mercados "tanto en el plano interno, a través del Derecho nacional, como en el plano exterior, mediante el establecimiento de normas internacionales creadas por acuerdo con otros Estados” (p. 28). De modo que el Derecho tiene como objetivo proporcionar seguridad jurídica a estas transacciones, las cuales deben juzgarse únicamente en función de su legalidad y, en razón al control de su cumplimiento.

Un cuerpo de principios generales se está consolidando en la arena global, en concordancia con el principio de legalidad (Cassese, 2005). En este escenario surge la reciprocidad como principio jurídico universal que incluye una expectativa de respeto mutuo, equiparación o de justicia conmutativa aplicable a varios tipos de relaciones, en el que también participan las económicas (Shing-I, 2009). Esta regla de conducta trasciende al ámbito normativo y posee efectos vinculantes. Además, el principio de reciprocidad se establece en el artículo 47 de la Convención de Viena, sobre relaciones diplomáticas 
de $1961^{7}$, la cual fue aprobada y ratificada por Colombia a través de la Ley 6 de 1972. Dentro de esta normativa se estipuló que ningún Estado receptor puede efectuar actos discriminatorios que afecten a otros Estados. Con base en lo anterior, este principio se incluyó en la Constitución Política de 1991 en los artículos 226 y $227^{8}$. En este sentido, de las normas citadas se desprende que la reciprocidad es la costumbre de un Estado que concede a otro, un trato semejante al que recibe de él, con base en la cooperación internacional. De nuevo, la reciprocidad es un término ambiguo por cuanto se puede referir a una política singular o un patrón sistémico de acción. Sin embargo, es usualmente invocada como un estándar de comportamiento apropiado que genera la cooperación entre Estados, solucionando conflictos y estableciendo un balance de poder (Keohane, 1986). Esta reciprocidad tiene un doble matiz: 1) es positiva si un Estado otorga ventajas que deben ser igualmente correspondidas; 2) negativa en tanto que ningún Estado está obligado con otro a hacer más concesiones que las que son otorgadas por aquel. En suma, la reciprocidad consiste entonces en una correspondencia mutua.

En el ámbito jurídico, como antecedente, este concepto de equivalencia fue incluido en la recopilación del Corpus Iuris Civilis del Di-

Esta norma establece lo siguiente: Artículo 47. 1.:

En la aplicación de las disposiciones de la presente Convención, el Estado receptor no hará ninguna discriminación entre los Estados. 2. Sin embargo, no se considerará como discriminatorio: a. que el Estado receptor aplique con criterio restrictivo cualquier disposición de la presente Convención, porque con tal criterio haya sido aplicada a su misión en el Estado acreditante; b. que, por costumbre 0 acuerdo, los Estados se concedan recíprocamente un trato más favorable que el requerido en las disposiciones de la presente Convención. (Convención de Viena sobre relaciones diplomáticas, 1961, art. 47).

8 Estos artículos establecen lo siguiente: Artículo 226. "El Estado promoverá la internacionalización de las relaciones políticas, económicas, sociales y ecológicas sobre bases de equidad, reciprocidad y conveniencia nacional” (Constitución Política de 1991, art. 226); Articulo 227.

El Estado promoverá la integración económica, social y política con las demás naciones y especialmente, con los países de América Latina y del Caribe mediante la celebración de tratados que sobre bases de equidad, igualdad y reciprocidad, creen organismos supranacionales, inclusive para conformar una comunidad latinoamericana de naciones. La ley podrá establecer elecciones directas para la constitución del Parlamento Andino y del Parlamento Latinoamericano. (Constitución Política de 1991, art. 227). 
gesto, el cual contiene y otorga valor a la locución latina do ut des (doy para que des), refiriéndose a las prestaciones de los contratos innominados que implican un intercambio de favores, o equilibrio entre beneficios y cesiones (Guzmán, 2003). Con esta acepción, la reciprocidad hace alusión a la aceptación de compromisos y normas plasmados en acuerdos suscritos entre particulares o tratados entre Estados. En estos se tienen derechos y deberes entre sí, siendo extensiva esta correspondencia a los procesos de contratación estatal. Posteriormente, en el siglo XVII, este principio se desarrolló a partir de la comitas gentium o cortesía internacional, en razón al efecto extraterritorial de las normas y la razón natural que exige una apertura de los sistemas a normas y decisiones extranjeras (Mesa-Moles, 2007). Esta fue una manera de responder a las restricciones que imponía la territorialidad al tráfico internacional. Sin duda, el interés común de los Estados en el respeto de las costumbres constituyó la base de este principio.

En este orden de ideas, la evolución del concepto de reciprocidad está de la mano del Derecho Internacional, lo que implica que la aplicación del derecho interno de un Estado a una persona física o jurídica no nacional se supedita al trato que se dé en aquel lugar a los nacionales de este país, es decir, "la ley territorial se aplica a los extranjeros $y$, en este sentido, prevea idéntico trato para los nacionales de aquel Estado" (Wolters Kluwer, s.f., p. 1). La reciprocidad implica acciones o concesiones que deben ser correspondidas, las cuales cesan cuando la reacción esperada no se produce (Keohane, 1986). Así, como aplicación de una regla tácita, un Estado está facultado a rechazar cierto acuerdo pactado con otro, en caso de que este último no siguiese hacia él una actitud afín con los alcances del trato.

El principio de reciprocidad tiene una dicotomía en su aplicación. En primer lugar, se entiende como la correlación de los derechos y deberes entre Estados en virtud de la suscripción de un tratado o acuerdo. En segunda instancia, es propio de las relaciones privadas donde existe la necesidad de dar cumplimiento a unas obli- 
gaciones correlativas y equivalentes entre sí en virtud de un contrato, garantizando las partes siempre el equilibrio de las prestaciones, tal como lo expresó Pastrana (2005):

El adjetivo recíproco es uno de los términos que con mayor frecuencia se utilizan en el lenguaje de la política y del derecho internacional. Sirve para caracterizar obligaciones mutuas, contraídas por dos o más sujetos de derecho internacional en cualquier esfera de las relaciones internacionales que, como efecto de una exigencia reforzada, no son consideradas como recíprocas sino a condición de procurarle a cada uno ventajas equivalentes (Pastrana, 2005, p. 88).

Lo anterior se encuentra asociado a la conmutatividad: no significa que la reciprocidad implique prestaciones idénticas, sino prestaciones equivalentes, en las que se establecen derechos y deberes correspondientes. En la materialización de estos vínculos, la reciprocidad implica un intercambio de conductas condicionadas de forma mutua en relación con la causa, efecto y forma. Como se insinuó, implica una conmutatividad consistente en el otorgamiento mutuo de beneficios y cargas equivalentes, basados en un equilibrio y justicia negocial. Hay que reconocer que, dependiendo del otorgamiento de ventajas o imposiciones, la reciprocidad puede ser considerada como positiva o negativa; o en razón a su alcance y dimensión como global o sectorial (Pastrana, 2005). Por consiguiente, se delimita su campo de acción.

De igual forma, la reciprocidad es específica cuando se presentan situaciones en las cuales las partes intercambian artículos o servicios de valor equivalentes. Esto se presenta en una secuencia estrictamente determinada que requiere un balance bilateral entre actores particulares. A su vez, esta es difusa cuando tiene una definición de equivalencia menos precisa en la que una de las partes puede ser vista como un grupo y no individualmente; además, la secuencia de eventos se encuentra menos delimitada. Este tipo de reciprocidad contiene la aceptación de estándares de comportamiento (Keohane, 
1986). En este sentido, la reciprocidad influye en la construcción de un tratado o acuerdo. Una vez se especifique el marco general en las negociaciones, se procede a materializar los acuerdos en razón a las ventajas, deberes o limitaciones que se establezcan. En palabras de Pastrana (2005), teniendo en cuenta la intención de las partes "la expectativa que genera el otorgamiento de ventajas mutuas permite que los estados cumplan, sin coacción externa, con la mayor parte de los acuerdos contraídos” (p. 91). Durante la etapa de negociación, las partes tienen la convicción de que se honre lo comprometido y, a la par, se establezca un marco de confianza y cumplimiento.

Es así como los tratados o acuerdos se construyen de forma voluntaria bajo este principio de reciprocidad (equiparable al principio de igualdad en las relaciones internacionales), así como los de buena fe y pacta sunt servanda. Esto se relaciona con lo establecido en el artículo 26 de la Convención de Viena sobre derecho de los tratados de $1969^{9}$, la cual fue aprobada y ratificada por Colombia a través de la Ley 32 de 1985. Sin perjuicio de la supremacía de la Constitución, el Estado debe respetar los compromisos internacionales adquiridos por el Estado que se incorporan a la legislación interna. Una obligación internacional contraída válidamente no puede ser modificada unilateralmente por el Estado en razón del principio de pacta sunt servanda (Rodríguez, 2016). Aunque los tratados internacionales sean equiparados jerárquicamente a las leyes internas, estos gozan de cierta primacía, por lo cual deben respetar los compromisos pac$\operatorname{tados}^{10}$. Sobre el particular se afirma lo siguiente:

Las actuaciones de la Administración pública no solo deberán respetar las leyes que tienen origen en el ordenamiento jurídico interno, sino también

9 Esta norma establece lo siguiente: Observancia de los tratados. 26. Pacta sunt servanda. "Todo tratado en vigor obliga a las partes y debe ser cumplido por ellas de buena fe" (Convención de Viena sobre derecho de los tratados, 1969).

10 Respecto a la justificación de la prevalencia de los tratados internacionales puede consultarse a Jiménez (1988). 
los principios y las reglas que se desprenden de los tratados internacionales que han sido debidamente incorporados al ordenamiento jurídico interno. Igualmente, el legislador, al expedir normas en materia administrativa, deberá también tener en cuenta lo dispuesto en los tratados internacionales (Rodríguez, 2016, p. 80).

Conviene distinguir que uno de los efectos del proceso de globalización jurídica y del surgimiento de un derecho administrativo global se fundamenta en la expansión del marco de aplicación de diversos principios jurídicos; los cuales están ligados al derecho a una buena administración pública (Ponce, 2010). El crecimiento del poder regulatorio trasnacional genera este Derecho Administrativo Global, el cual fue delimitado por Kingsbury, Krisch y Stewart (2010) de la siguiente manera:

Aquél que incluye los mecanismos, principios, prácticas y los acuerdos sociales que los respaldan y que promueven o que de otra forma afectan la accountability $^{11}$ de los órganos globales administrativos, en particular asegurándose de que cumplan con los estándares adecuados de transparencia, participación, toma de decisiones razonada, y legalidad, y promoviendo la efectiva evaluación de las normas y decisiones que aprueban (pp. 6-7).

En correspondencia con lo dicho, las medidas adoptadas por los Estados deben estar en concordancia con sus obligaciones internacionales. Los instrumentos tradicionales no son suficientes para gobernar, sino que es necesario reconocer otras fuentes diferentes a la soberanía de la voluntad. De modo que existe un pluralismo normativo que afecta las fuentes nacionales (Campanelli, 2018). Cuando las disposiciones supranacionales no son respetadas por la normativa interna, se genera un desequilibrio a favor de un Estado en detrimento de otro. Por lo que es natural que se adopten medidas para corregirlo, por ejemplo, la aceleración de la política de disminución

11 La traducción al español del término accountability más aceptada es "rendición de cuentas". 
de gravámenes y restricciones por parte del Estado, beneficiado con la ventaja o el retardo, e incluso, la interrupción del ritmo de disminución de los derechos y restricciones por parte del Estado lesionado (Prebisch, 1962; Keohane, 1986). En razón a la teoría de la ventaja comparativa, las utilidades y el bienestar general son mayores cuanto más elevado sea el número de países que liberalizan sus relaciones económicas con el exterior; en ese sentido, se aplican ciertas acciones:

El principio de reciprocidad ayuda a alcanzar un doble objetivo: en primer lugar, provoca un efecto multiplicador del comercio, al obligar a los países a suprimir medidas proteccionistas para beneficiarse de las oportunidades que ofrecen los mercados internacionales: en segundo lugar, facilita la aceptación interna de los acuerdos de liberalización, ya que permite identificar las ventajas que obtendrán los sectores de producción que se verán beneficiados (Hinojosa, 2010, pp. 42-43).

En concordancia con los principios de la función pública, establecidos en el artículo 209 de la Carta Política, el principio de reciprocidad en materia de contratación estatal en Colombia fue desarrollado por el artículo 20 de la Ley 80 de $1993^{12}$. En este se

12 Esta norma establece lo siguiente: artículo 20. De la Reciprocidad. En los procesos de contratación estatal se concederá al proponente de bienes y servicios de origen extranjero, el mismo tratamiento y en las mismas condiciones, requisitos, procedimientos y criterios de adjudicación que el tratamiento concedido al nacional, exclusivamente bajo el principio de reciprocidad. Se entiende por principio de reciprocidad, el compromiso adquirido por otro país, mediante acuerdo, tratado o convenio celebrado con Colombia, en el sentido de que a las ofertas de bienes y servicios colombianos se les concederá en ese país el mismo tratamiento otorgado a sus nacionales en cuanto a las condiciones, requisitos, procedimientos y criterios para la adjudicación de los contratos celebrados con el sector público. PARÁGRAFO 10. El Gobierno Nacional, en los acuerdos, tratados o convenios que celebre para estos efectos, deberá establecer todos los mecanismos necesarios para hacer cumplir el tratamiento igualitario entre el nacional y el extranjero tanto en Colombia como en el territorio del país con quien se celebre el mencionado acuerdo, convenio o tratado. PARÁGRAFO 20. Cuando para los efectos previstos en este artículo no se hubiere celebrado acuerdo, tratado 0 convenio, los proponentes de bienes y servicios de origen extranjero podrán participar en los procesos de contratación en las mismas condiciones y con los mismos requisitos exigidos a los nacionales colombianos, siempre y cuando en sus respectivos países los proponentes de bienes y servicios de origen colombiano gocen de iguales oportunidades. El Gobierno Nacional establecerá los mecanismos para asegurar el cumplimiento de la reciprocidad prevista en este parágrafo. (Ley 80 de 1993, art. 20) 
estableció un concepto de igualdad entre el colombiano y el extranjero en procesos de selección estatales, señalando que los tratados o convenios suscritos que eliminan restricciones, a su vez, fundamentan la reciprocidad. En este sentido, Dávila (2016) comentó que "la concepción de la reciprocidad comenzó a transformarse hacia un concepto de igualdad entre extranjero y colombiano en nuestros procesos de selección” (p. 232). Si se observa con detalle esta idea, la reciprocidad entonces consiste en dar el mismo tratamiento que los oferentes extranjeros brindan en un plano de igualdad. Mirándolo así, los nacionales colombianos también deben gozar de igualdad en procesos de selección extranjeros desarrollados por Estados con los que se han suscrito acuerdos.

La norma citada incluye la expresión "acuerdos, tratados y convenios" que, para efectos de la contratación estatal, es asimilada a la de "acuerdos comerciales" que contienen derechos y obligaciones en materia de compras públicas, de conformidad con el Decreto 1082 de $2015^{13}$. El Estado colombiano ha sido signatario de varios acuerdos comerciales ${ }^{14}$ que reúnen capítulos referentes a la adquisición de bienes y servicios requeridos por entidades estatales que han forzado la modificación sustancial de instituciones jurídicas (Benavides, 2014). Con la suscripción de estos acuerdos, se adoptan estándares internacionales referentes a procedimientos y lineamientos en materia de contratación pública. Por ende, existe un proceso de adaptación de la normativa interna aplicable, en aras de proteger la inversión extranjera para incentivarla. Relacionado con lo anterior, Rojas (2011) aseguró lo siguiente:

13 La definición de Acuerdos Comerciales contenida en el Decreto 1082 de 2015 es la siguiente: "Tratados internacionales vigentes celebrados por el Estado colombiano, que contienen derechos y obligaciones en materia de compras públicas, en los cuales existe como mínimo el compromiso de trato nacional para: (i) los bienes y servicios de origen colombiano y (ii) los proveedores colombianos" (Decreto 1082 de 2015, artículo 2.2.1.1.1.3.1).

14 Los acuerdos vigentes de libre comercio que contienen capítulos de compras públicas suscritos por Colombia pueden consultarse en el siguiente enlace: http://www.tlc.gov.co/acuerdos/vigente 
(...) el poder de autodeterminación normativa del país se ve relativizado por el mencionado acuerdo o por cualquier otro TLC o acuerdo internacional celebrado sobre la materia. Esta situación es la expresión de la globalización jurídica, así como de una de sus características: la relativización de la soberanía nacional (Rojas, 2011, p. 318).

La reciprocidad puede constituir una estrategia para la apertura de mercados extranjeros, así como el establecimiento de un balance bilateral de comercio. Además, los acuerdos que contienen capítulos de compras públicas también implican la condición de nación más favorecida $(\mathrm{NMF})^{15}$. Dicho de otra manera, es la aplicación automática del mejor tratamiento que ya se ha concedido, materializando una reciprocidad agresiva. Esta situación refleja el concepto de reciprocidad específica, diferente al tratamiento sin condiciones que implica la reciprocidad difusa (Keohane, 1986). En este contexto, el Decreto 1082 de 2015 asimila la reciprocidad a la expresión "trato nacional", definición que no debe confundirse con la preferencia a las ofertas nacionales, señalando sus mismos efectos en materia de compras públicas ${ }^{16}$. Esta expresión es utilizada por la Agencia Nacio-

15 La cláusula o condición de "nación más favorecida" (NMF) hace parte de los principios del sistema de comercio, desarrollados en los Acuerdos de la Organización Mundial del Comercio (OMC). Sobre el particular puede consultarse el siguiente enlace: https://www.wto.org/spanish/thewto_s/whatis s/tif s/fact2 s.htm

16 Esta norma establece Io siguiente: Artículo 2.2.1.2.4.1.3. Existencia de trato nacional. La Entidad Estatal debe conceder trato nacional a: (a) los oferentes, bienes y servicios provenientes de Estados con los cuales Colombia tenga Acuerdos Comerciales, en los términos establecidos en tales Acuerdos Comerciales; (b) a los bienes y servicios provenientes de Estados con Ios cuales no exista un Acuerdo Comercial pero respecto de los cuales el Gobierno Nacional haya certificado que los oferentes de Bienes y Servicios Nacionales gozan de trato nacional, con base en la revisión y comparación de la normativa en materia de compras y contratación pública de dicho Estado; y (c) a los servicios prestados por oferentes miembros de la Comunidad Andina de Naciones teniendo en cuenta la regulación andina aplicable a la materia. El Ministerio de Relaciones Exteriores debe expedir el certificado por medio del cual se acredite la situación mencionada en el literal (b) anterior en relación con un Estado en particular, lo cual no es requerido para acreditar las situaciones a las que se refieren los literales (a) y (c) anteriores. Para constatar que los oferentes de Bienes y Servicios Nacionales gozan de trato nacional en un Estado, el Ministerio de Relaciones Exteriores debe revisar y comparar la normativa en materia de compras y contratación pública del respectivo Estado para lo cual puede solicitar el apoyo técnico del Ministerio de Comercio, Industria y Turismo y de Colombia 
nal de Contratación, Colombia Compra Eficiente, de forma indistinta con la reciprocidad, asignándole un tratamiento equivalente ${ }^{17}$, mientras que la referida preferencia que se establece en normas de igual o inferior jerarquía es producto de la extensa regulación de la contratación pública en Colombia, aumentando el riesgo de contradicción de estas normas con los tratados internacionales (Benavides, 2014). En este sentido, la fuerza vinculante de estos acuerdos impone a los signatarios la armonización de sus disposiciones sobre la legislación interna.

El principio de reciprocidad va de la mano con el principio de igualdad contenido en la Constitución Política, como lo afirmó Pardo (2011), "además de los postulados generales impuestos por el preámbulo Constitucional y los artículos $1^{\circ}$ y 13 ibídem de la Carta, el artículo 209 superior dispone que la función administrativa debe desarrollarse con fundamento, entre otros, en el principio de igualdad” (Pardo, 2011, p. 78). En materia de contratación estatal, este principio propende por el libre acceso a la misma: los interesados y participantes en un proceso de selección deben encontrarse en igual situación, obtener las mismas facilidades y estar en posibilidad de efectuar sus ofertas sobre las mismas bases y con-

Compra Eficiente, dentro de sus competencias legales. Los certificados para acreditar la condición a la que se refiere el literal (b) anterior deben ser publicados en la forma y oportunidad que para el efecto disponga Colombia Compra Eficiente. La vigencia de los certificados será de dos años contados a partir de la fecha de su expedición, sin perjuicio de que el Ministerio de Comercio, Industria y Turismo o Colombia Compra Eficiente soliciten al Ministerio de Relaciones Exteriores su revisión con ocasión de la expedición de nueva normativa en el Estado sobre el cual se expide el certificado. Colombia Compra Eficiente puede determinar vía circular la forma como el Ministerio de Relaciones Exteriores debe constatar que los oferentes de Bienes y Servicios Nacionales gozan de trato nacional y de revisar y comparar la normativa en materia de compras y contratación pública para la expedición del certificado (Decreto 1082 de 2015, artículo 2.2.1.2.4.1.3).

17 La Agencia Nacional de Contratación, Colombia Compra Eficiente, elaboró un documento guía sobre aplicación de Acuerdos Comerciales en procesos de selección adelantados por entidades estatales, destinado a los partícipes de la contratación pública denominado "Manual para el manejo de los Acuerdos Comerciales en Procesos de Contratación" cuya versión actual es M-MACPC-14, el cual puede consultarse en el siguiente enlace: https://www.colombiacompra.gov.co/sites/cce_public/files/cce documents/cce manual acuerdos comerciales.pdf 
diciones (Dávila, 2016). Para cumplir los fines de Estado a través de la contratación estatal y, a su vez, obtener la oferta más beneficiosa, la Carta Política otorga las oportunidades (en igualdad de condiciones) para participar en sus procesos de selección a todos aquellos que se encuentren en capacidad de ofertar lo requerido sin discriminación alguna. La aplicación de principios de nivel global a sistemas domésticos genera una problemática en relación con el derecho administrativo interno. Dentro de este ámbito, es oportuno mencionar la participación abierta en procesos contractuales estatales, los cuales son usados para perseguir fines como el desarrollo de una zona particular y el establecimiento de ciertos criterios preferenciales (Cassese, 2005). De esta forma, con el pretexto de apoyar a la industria nacional y ofrecer otro tipo de incentivos cuya eficacia no se evidencia en la práctica, en Colombia el legislador y el ejecutivo han introducido disposiciones que contravienen los cometidos constitucionales, lo que obstaculiza la integración y el cumplimiento de compromisos internacionales.

En relación con lo anterior, Rodríguez-Arana (2011) aseveró lo que a continuación se cita:

En materia de contratación pública, nos topamos con un problema complejo, dado que en el espacio europeo resulta que el principio de igualdad de trato es desconocido muchas veces a favor de las empresas nacionales por diferentes "razones": desde la promoción de la industria nacional hasta la protección de la economía propia (p. 34).

Quienes establecen las políticas estatales a menudo tratan de combinar la reciprocidad específica con la difusa, lo que en la realidad genera una ambigüedad cuyo efecto son las dificultades para aplicarla (Keohane, 1986). Esto ocasiona que en la actualidad se apliquen, de manera general y transversal, a todos los procesos de selección regidos por el Estatuto General de Contra- 
tación Pública. Estos criterios de calificación otorgan a la oferta nacional una ventaja injustificada, limitando el principio de reciprocidad establecido en la Constitución y acuerdos internacionales. Así, es oportuno aclarar que, alrededor del particular, se concluye esto:

(...) estas disposiciones de protección chocan con el principio de igual tratamiento de nacionales establecidos en los acuerdos de libre comercio y, dado el carácter supra legal de estos, se planteará el tema de la inexequibilidad de estas distintas leyes. De hecho, las mismas leyes transcritas establecen, con cierta hipocresía, la necesidad de consultar los acuerdos internacionales (Benavides, 2014, p. 36).

Debido a esto es que el principio de reciprocidad se limita en razón al proteccionismo y la preferencia de empresas nacionales para la adjudicación de contratos públicos. Los procesos de selección para adjudicar contratos financiados con recursos públicos deben procurar por el cumplimiento del interés general al tener como objeto obras y servicios de calidad que permitan la mejora de las condiciones de vida de los administrados (Rodríguez-Arana, 2011). En el marco de la actividad contractual estatal, debe quedar claro que las ofertas seleccionadas deben ser las más idóneas en sus aspectos jurídicos, financieros y técnicos sin importar su nacionalidad.

Es pertinente entonces establecer las condiciones que limitan la reciprocidad en los procesos de selección adelantados por entidades estatales en Colombia. En primer lugar, la Ley 816 de 2003 estableció un criterio de calificación consistente en la asignación de un puntaje comprendido entre el $10 \%$ y el $20 \%$ de la calificación total de los procesos públicos de selección que se adelanten para la adquisición de bienes o servicios o entre el $5 \%$ y el $15 \%$ por la incorporación de componente colombiano de bienes y servicios profesionales, técnicos y operativos. Por úl- 
timo, estableció un criterio de desempate, favoreciendo en estos casos a la oferta nacional sobre la extranjera ${ }^{18}$.

Respecto a la inclusión de estas condiciones, después de una década de vigencia de la Ley 80 de 1993, el legislador estableció como justificación la implementación de una política de fortalecimiento a la economía a través de mecanismos que contribuyeran a impulsar al sector productivo nacional, como la compra de bienes y servicios de origen nacional por parte de las entidades estatales. De igual forma, consideró que debía restaurarse el equilibrio en la participación de proveedores nacionales y extranjeros en las licitaciones públicas, en razón a que la Ley 80 de 1993 tenía condiciones desfavorables para los proveedores nacionales ${ }^{19}$.

Al considerar al Estado como principal contratante del país y advertir que las compras públicas representaban un porcentaje considerable del PIB, justificando la mencionada política económica, el legislador y el ejecutivo, posteriormente, introdujeron al ordenamiento jurídico nacional otras disposiciones que limitan el principio de reciprocidad en la contratación estatal. Estas estaban referidas a las oportunidades de negocio relevantes para las mipymes, entendidas como unidades de explotación económica, realizadas por personas naturales o jurídicas, en actividades empresariales, agropecuarias, industriales, comerciales o de servicios,

18 Esta norma establece lo siguiente: Artículo 20. Las entidades de que trata el artículo $1^{\circ}$ asignarán, dentro de los criterios de calificación de las propuestas, un puntaje comprendido entre el diez (10) y el veinte por ciento (20\%), para estimular la industria colombiana cuando los proponentes oferten bienes 0 servicios nacionales. Tratándose de bienes 0 servicios extranjeros, la entidad contratante establecerá un puntaje comprendido entre el cinco (5) y el quince por ciento (15\%), para incentivar la incorporación de componente colombiano de bienes y servicios profesionales, técnicos y operativos. Si una vez efectuada la calificación correspondiente, la oferta de un proponente extranjero se encuentra en igualdad de condiciones con la de un proponente nacional, se adjudicará al nacional. (Ley 816 de 2003, Art. 2)

19 La exposición de motivos de la Ley 816 de 2003 puede consultarse en la Gaceta del Congreso No. 476 de septiembre 20 de 2001, a través del siguiente enlace: http://www.lexbasecolombia.net/lexbase/gacetas/2001/gc0476de2001.htm 
rural o urbana, que cumplan con los parámetros establecidos en la Ley 590 de $2000^{20}$.

En este sentido, con la modificación al sistema de compras públicas por parte de la Ley 1150 de 2007 se desarrolló la política de participación de las mipymes en la contratación estatal, buscando favorecer a estas organizaciones empresariales con condiciones especiales ${ }^{21}$.

En razón a lo anterior, a través del Decreto 1082 de 2015, el ejecutivo reglamentó las disposiciones referentes a convocatorias limitadas a mipymes y convocatorias limitadas territorialmente. En el primer caso, si el presupuesto oficial del proceso contractual es inferior a

20 Esta norma contiene las siguientes disposiciones: Artículo 20. Definiciones. Para todos los efectos, se entiende por empresa, toda unidad de explotación económica, realizada por persona natural o jurídica, en actividades agropecuarias, industriales, comerciales o de servicios, en el área rural o urbana. Para la clasificación por tamaño empresarial, entiéndase micro, pequeña, mediana y gran empresa, se podrá utilizar uno o varios de los siguientes criterios: 1. Número de trabajadores totales. 2. Valor de ventas brutas anuales. 3. Valor activos totales. Para efectos de los beneficios otorgados por el Gobierno nacional a las micro, pequeñas y medianas empresas el criterio determinante será el valor de ventas brutas anuales. Parágrafo 10. El Gobierno Nacional reglamentará los rangos que aplicarán para los tres criterios e incluirá especificidades sectoriales en los casos que considere necesario. Parágrafo 20. Las definiciones contenidas en el artículo 20 de la Ley 590 de 2000 continuarán vigentes hasta tanto entren a regir las normas reglamentarias que profiera el Gobierno Nacional en desarrollo de lo previsto en el presente artículo. (1. Mediana empresa: a) Planta de personal entre cincuenta y uno (51) y doscientos (200) trabajadores, o b) Activos totales por valor entre 100.000 a 610.000 UVT. 2. Pequeña empresa: a) Planta de personal entre once (11) y cincuenta (50) trabajadores, 0 b) Activos totales por valor entre quinientos uno (501) y menos de cinco mil (5.000) salarios mínimos mensuales legales vigentes 0 , 3. Microempresa: a) Planta de personal no superior a Ios diez (10) trabajadores $0, b)$ Activos totales excluida la vivienda por valor inferior a quinientos (500) salarios mínimos mensuales legales vigentes. (Ley 590 de 2000, art. 2)

21 Esta norma establece lo siguiente: Artículo 12. Promoción del desarrollo en la contratación pública.

De conformidad con lo dispuesto en los artículos 13, 333 y 334 de la Constitución Política, el Gobierno Nacional definirá las condiciones y los montos de acuerdo con los compromisos internacionales vigentes, para que en desarrollo de los procesos de selección, las entidades estatales adopten en beneficio de las Mipymes, convocatorias limitadas a estas en las que, previo a la Resolución de apertura del proceso respectivo, se haya manifestado el interés del número plural de Mipymes que haya sido determinado en el reglamento. Asimismo, el reglamento podrá establecer condiciones preferenciales en favor de la oferta de bienes y servicios producidos por las Mipymes, respetando los montos y las condiciones contenidas en los compromisos internacionales vigentes. En todo caso, se deberá garantizar la satisfacción de las condiciones técnicas y económicas requeridas en la contratación y, realizarse la selección 
ciento veinticinco mil dólares (125 000 USD) y se reciben solicitudes de al menos tres (3) mipymes nacionales, se procederá a limitar el proceso a este tipo de oferentes ${ }^{22}$. En el segundo caso, las entidades

de acuerdo con las modalidades de selección a las que se refiere el Estatuto General de Contratación de la Administración Pública. De igual forma, en los pliegos de condiciones las entidades estatales, dispondrán, de mecanismos que fomenten en la ejecución de los contratos estatales la provisión de bienes y servicios por población en pobreza extrema, desplazados por la violencia, personas en proceso de reintegración y, sujetos de especial protección constitucional en las condiciones que señale el reglamento; siempre que se garanticen las condiciones de calidad y cumplimiento del objeto contractual. Parágrafo $1^{\circ}$. En los procesos de selección que se desarrollen con base en el primer inciso, las entidades podrán realizar las convocatorias limitadas que beneficien a las Mipymes del ámbito municipal o departamental correspondiente al de la ejecución del contrato. Parágrafo $2^{\circ}$. Sin perjuicio de lo dispuesto en los artículos 5 y 6 de la Ley 1150 de 2007, para que las Mipymes puedan participar en las convocatorias a las que se refiere este artículo, deberán acreditar como mínimo un año de existencia, para lo cual deberán presentar el certificado expedido por la cámara de comercio o por la autoridad que sea competente para dicha acreditación. Parágrafo $3^{\circ}$. En la ejecución de los contratos a que se refiere el presente artículo, las entidades y los contratistas, deberán observar lo dispuesto en los artículos 90 a 95 de la Ley 418 de 1997 y las normas que la modifiquen, adicionen o subroguen. Parágrafo $4^{\circ}$. Criterio de desempate. En los procesos de contratación públicos, en caso de empate en la puntuación de dos o más proponentes, se preferirá a aquel que demuestre la vinculación del mayor porcentaje de personas mayores que no sean beneficiarios de la pensión de vejez, familiar 0 de sobrevivencia y que hayan cumplido el requisito de edad de pensión establecido en la Ley. Para los efectos de este parágrafo solo se tendrá en cuenta la vinculación de aquellos adultos mayores objeto de esta Ley que hayan estado vinculados con una anterioridad igual o mayor a un año. Para los casos de constitución inferior a un año se tendrá en cuenta a aquellos trabajadores que hayan estado vinculados desde el momento de constitución de la misma. Dado el caso en que el contrato público haya sido obtenido con ocasión a esta forma de desempate, el empleador deberá mantener el mismo porcentaje de adultos mayores trabajadores al interior de la empresa durante la vigencia de ejecución del contrato. En caso contrario no podrá hacer uso de este beneficio en cualquier otro contrato que celebre con el Estado dentro de los 5 años siguientes a la terminación del contrato. Para estos efectos, la persona natural, el representante legal de la persona jurídica o el revisor fiscal, según corresponda, certificará, bajo la gravedad de juramento, el número total de trabajadores vinculados a la planta de personal del proponente o sus integrantes que cumplan con lo aquí señalado a la fecha de cierre del proceso de selección (Ley 1150 de 2007, art. 12).

22 Esta norma establece lo siguiente: Artículo 2.2.1.2.4.2.2. Convocatorias limitadas a Mipyme. La Entidad Estatal debe limitar a las Mipyme nacionales con mínimo un (1) año de existencia la convocatoria del Proceso de Contratación en la modalidad de licitación pública, selección abreviada y concurso de méritos cuando: 1. El valor del Proceso de Contratación es menor a ciento veinticinco mil dólares de los Estados Unidos de América (US\$125.000[sic]), liquidados con la tasa de cambio que para el efecto determina cada dos años el Ministerio de Comercio, Industria y Turismo; y 2. La Entidad Estatal ha recibido solicitudes de por lo menos tres (3) Mipyme nacionales para limitar la convocatoria a Mipyme nacionales. La Entidad Estatal debe recibir estas solicitudes por lo menos un (1) día hábil antes de la apertura del Proceso de Contratación. (Decreto 1082 de 2015, artículo 2.2.1.2.4.2.2) 
estatales de forma discrecional pueden establecer convocatorias limitadas territorialmente a ciertos departamentos o municipios ${ }^{23}$. Como regla adicional para este tipo de convocatorias, el citado Decreto establece que las entidades estatales solo deben aceptar ofertas de mipymes o estructuras plurales formadas únicamente por mipymes ${ }^{24}$.

Una vez establecidas las limitaciones al principio de reciprocidad en materia de contratación estatal, se puede concluir que la reciprocidad consiste en otorgar un trato semejante al que se recibe por parte de otro sujeto de derecho internacional, sin ejercer actos discriminatorios. Así, delimitado el concepto de reciprocidad y su aplicación en la contratación estatal en Colombia, se procede en la siguiente sección a analizar su desarrollo jurisprudencial por parte de la Corte Constitucional, para concluir si el apoyo a la industria nacional y los incentivos a la contratación estatal referentes a las convocatorias limitadas restringen este principio.

\section{Análisis jurisprudencial de la reciprocidad en tratados internacionales suscritos por Colombia que contienen capítulos de compras públicas}

Con base en el concepto de reciprocidad en materia de contratación estatal, se procede a establecer su tratamiento jurisprudencial por parte de la Corte Constitucional respecto a los tratados internacionales

23 Esta norma establece lo siguiente: Artículo 2.2.1.2.4.2.3. Limitaciones territoriales. Las Entidades Estatales pueden realizar convocatorias limitadas a Mipyme nacionales domiciliadas en los departamentos o municipios en donde se va a ejecutar el contrato. La Mipyme debe acreditar su domicilio con el registro mercantil 0 el certificado de existencia y representación legal de la empresa. (Decreto 1082 de 2015, artículo 2.2.1.2.4.2.3)

24 Esta norma establece lo siguiente: Artículo 2.2.1.2.4.2.4. Acreditación de requisitos para participar en convocatorias limitadas. La Mipyme nacional debe acreditar su condición con un certificado expedido por el representante legal y el revisor fiscal, si está obligado a tenerlo, o el contador, en el cual conste que la Mipyme tiene el tamaño empresarial establecido de conformidad con la ley. En las convocatorias limitadas, la Entidad Estatal debe aceptar solamente las ofertas de Mipyme, consorcios o uniones temporales formados únicamente por Mipyme y promesas de sociedad futura suscritas por Mipyme. (Decreto 1082 de 2015, artículo 2.2.1.2.4.2.4) 
suscritos por Colombia que incluyen capítulos de compras públicas, a fin de analizar la concordancia de los compromisos adquiridos por Colombia. Asimismo, se analizan las limitaciones establecidas en el artículo 2 de la Ley 816 de 2003 (referente al apoyo a la industria nacional) y los artículos 2.2.1.2.4.2.2, 2.2.1.2.4.2.3 y 2.2.1.2.4.2.4 de la sección 4 del Decreto 1082 de 2015 (referentes a convocatorias limitadas).

La línea jurisprudencial de la Corte Constitucional referente a la reciprocidad en materia de contratación estatal tuvo un mayor desarrollo a partir del año 2008. Esto debido a que, en el periodo comprendido entre 1992 y 2007, dicha corporación desarrolló la aplicación en Colombia del principio de reciprocidad en materia de Derecho Internacional, pero enfocado hacia las disposiciones de trato nacional en un marco general de liberalización del comercio de servicios entre privados y las cláusulas de nación más favorecida en desgravación arancelaria. De esta forma, en una primera instancia, la jurisprudencia analizó los compromisos pactados en instrumentos, por los cuales se conformaron bloques económicos cuyo común denominador fue la citada inclusión de la condición de trato nacional y la cláusula de nación más favorecida.

Durante este primer periodo, la Corte Constitucional analizó la reciprocidad y los alcances de los tratados internacionales ${ }^{25}$ y los

25 Sobre el particular puede consultarse la siguiente jurisprudencia de la Corte Constitucional: Sentencia C-564 de 1992, Sentencia C-574 de 1992, Sentencia C-025 de 1993, Sentencia C-227 de 1993, Sentencia C-276 de 1993, Sentencia C-280 de 1994, Sentencia C-137 de 1995, Sentencia C-203 de 1995, Sentencia C-216 de 1996, Sentencia C-358 de 1996, Sentencia C-379 de 1996, Sentencia C-442 de 1996, Sentencia C-682 de 1996, Sentencia C-008 de 1997, Sentencia C-231 de 1997, Sentencia C-323 de 1997, Sentencia C-421 de 1997, Sentencia C-468 de 1997, Sentencia C-562 de 1997, Sentencia C-400 de 1998, Sentencia C-492 de 1998, Sentencia C-494 de 1998, Sentencia C-228 de 1999, Sentencia C-246 de 1999, Sentencia C-405 de 1999, Sentencia C-719 de 1999, Sentencia C-327 de 2000, Sentencia C-393 de 2000, Sentencia C-279 de 2001, Sentencia C-809 de 2001, Sentencia C-861 de 2001, Sentencia C-1147 de 2001, Sentencia C-294 de 2002, Sentencia C-334 de 2002, Sentencia C-369 de 2002, Sentencia C-578 de 2002, Sentencia C-581 de 2002, Sentencia C-887 de 2002, Sentencia C-309 de 2004, Sentencia C-644 de 2004, Sentencia C-1153 de 2005, Sentencia C-863 de 2006, Sentencia C-864 de 2006, Sentencia C-933 de 2006, Sentencia C-309 de 2007, Sentencia C-718 de 2007. 
compromisos adquiridos en uno o varios instrumentos en desarrollo de la Convención de Viena sobre el Derecho de los tratados, así como su armonización con el Derecho interno, otorgando relevancia al principio de pacta sunt servanda, en virtud del cual todo tratado en vigor obliga a las partes y debe ser cumplido por ellas de buena fe. Esto, sin poder invocar las disposiciones de su derecho interno como justificación del incumplimiento de un tratado.

Relacionado con lo anterior, la Corte Constitucional concluyó que los únicos tratados internacionales suscritos por Colombia que tienen una jerarquía normativa superior a la de las leyes ordinarias son los que reconocen derechos humanos y que prohíben su limitación en los estados de excepción. Dicha jerarquía superior no se extiende a los tratados suscritos en materia económica y comercial por cuanto su objeto corresponde a la ordenación de aspectos económicos, comerciales, fiscales, aduaneros, inversiones, técnicos, etc.

La Corte considera la cláusula de trato nacional pactada en tratados internacionales compatible con la Constitución por cuanto busca eliminar el trato discriminatorio que pudiera presentarse entre los nacionales y extranjeros en relación con el comercio de mercancías. Con ella se garantiza el derecho a la igualdad, al colocar en condiciones de igualdad jurídica a las inversiones de extranjeros y nacionales. De esta forma, es congruente con los imperativos constitucionales de promover la integración económica sobre bases de equidad y reciprocidad, principios de derecho internacional aceptados por Colombia. El mismo análisis efectuado por la Corte Constitucional recae sobre el principio de nación más favorecida. La corporación considera que, con base en este principio, un Estado se obliga a dar a otro un trato no menos favorable que el que se concede a sus propios nacionales o a los nacionales de cualquier tercer Estado, por lo cual se encuentra ajustado a la carta política. 
Uno de los primeros casos fue el de la Comunidad Andina (CAN), Acuerdo Subregional Andino o Pacto de Cartagena de 1969, en su momento examinado por la Corte Suprema de Justicia, incorporado al ordenamiento interno mediante la Ley 8 de 1973, e integrada actualmente por Colombia, Ecuador, Bolivia y Perú. Otro ejemplo es el de la Asociación Latinoamericana de Integración (ALADI) (Argentina, Bolivia, Brasil, Chile, Colombia, Cuba, Ecuador, México, Panamá, Paraguay, Perú, Uruguay y Venezuela), creada por el Tratado de Montevideo de 1980, que en su momento fue examinado por la Corte Suprema de Justicia e incorporado al ordenamiento interno mediante la Ley 45 de 1981. Esta organización dio paso a la creación del Mercado Común del Sur (Mercosur) en 1991. Derivado del mencionado tratado, el acuerdo suscrito con la Comunidad del Caribe (CARICOM) (integrada por Antigua y Barbuda, Barbados, Belice, Dominica, Granada, Guyana, Jamaica, Montserrat, San Cristóbal y Nieves, Santa Lucía, San Vicente y las Granadinas, Trinidad y Tobago) fue desarrollado por el Decreto 2891 de 1994.

En este primer periodo, se destacó la Sentencia C-178 de 1995, considerada como sentencia hito por contener el primer análisis respecto a un capítulo dedicado exclusivamente a compras del sector público, establecido en el Tratado de Libre Comercio (TLC) entre Colombia, México y Venezuela, incorporado al ordenamiento interno mediante la Ley 172 de 1994 y examinada por la Corte Constitucional a través de la mencionada jurisprudencia. En esta sentencia, se señaló que, para entonces, en el ámbito de la CAN no existía regulación expresa respecto a las compras públicas, por lo que la inclusión de este capítulo representó un avance para las relaciones comerciales entre las partes. En el capítulo XV, referente a compras del sector público, se establecieron condiciones de trato nacional en las compras que realizaban las entidades del Estado.

En este sentido, el artículo 15-04, respecto al trato nacional y no discriminación, y trato de nación más favorecida, establece 
que cada parte otorga a los bienes de otra a los proveedores de esos bienes y a los proveedores de servicios de otra parte, un trato no menos favorable que el más favorable otorgado: a sus propios bienes y proveedores, y a los bienes y proveedores de otra parte. De igual forma, prohíbe dar a un proveedor establecido en su territorio un trato menos favorable que el otorgado a otro proveedor establecido en ese territorio, en razón del grado de afiliación o de propiedad extranjeras, o discriminar a un proveedor establecido en su territorio en razón de que los bienes o servicios ofrecidos por ese proveedor para una compra particular sean bienes o servicios de otra parte.

Respecto a las condiciones de participación contenidas en el artículo 15-12, se destacan las siguientes: 1) con la finalidad de garantizar una óptima competencia efectiva entre los proveedores de las partes en los procedimientos de licitación selectiva, una entidad invita, para cada compra, al mayor número de proveedores nacionales y de proveedores de las otras partes que sea compatible con el funcionamiento eficiente del sistema de compras. 2) El número de proveedores adicionales autorizados a participar solo está limitado por razones del funcionamiento eficiente del sistema de compras.

De lo anterior se deduce que no puede imponérsele a los oferentes extranjeros condiciones restrictivas para participar en los procesos de selección adelantados por entidades estatales. Por otro lado, pese a que se establece el procedimiento de selección limitado, como la licitación restringida de la que habla el artículo 15-16, se prohíbe su uso si tiene la finalidad de evitar la máxima competencia posible o si constituye un medio de discriminación entre proveedores de las otras partes o de protección a los proveedores nacionales.

Sobre este tratado, la Corte Constitucional establece que sus cláusulas particulares están dirigidas a la integración de mercados entre los Estados parte, bajo el entendido que ese proceso de libe- 
ralización cumple con el mandato constitucional de internacionalización de las relaciones económicas que no incorpora tratamientos contrarios a los criterios de equidad, proporcionalidad y conveniencia nacional, a que a la vez que deja incólumes los derechos constitucionales y las competencias de los órganos del Estado. Resalta que la cláusula de la nación más favorecida constituye un principio básico del derecho internacional aplicable en condiciones igualitarias para todos los Estados parte, por lo que, si un país otorga una condición más favorable a un tercer Estado, nace para los demás Estados interesados la extensión de las ventajas concedidas, lo que permite garantizar los principios de igualdad, reciprocidad y equidad en el proceso de integración comercial (arts. 150-16, 226 y 227 de la Constitución).

La negociación del TLC con México y Venezuela en 1994 estableció unos estándares para los equipos negociadores de los subsiguientes tratados en materia económica, los cuales contienen disposiciones sobre contratación pública. Se mantienen entonces los principios de trato nacional y no discriminación, obligando a las partes a otorgar incondicionalmente a las mercancías y servicios de la otra parte y a los proveedores de tales mercancías y servicios un trato no menos favorable que el trato más favorable otorgado por dicha parte a sus propias mercancías, servicios y proveedores. Debido a ello, ninguna de las partes puede tratar a un oferente de manera menos favorable que a otro por su nacionalidad.

En este sentido, los subsiguientes acuerdos imponen a las entidades contratantes ceñirse a condiciones esenciales para garantizar que el oferente cuente con la capacidad, comercial, técnica y financiera para cumplir con los requisitos y las especificaciones técnicas de la contratación. Esto quiere decir que, en desarrollo del principio de selección objetiva, no deben establecerse condiciones diferentes a las requeridas para acreditar capacidad jurídica, financiera y técnica que permita ejecutar adecuadamente el contrato derivado del 
proceso de selección, como condiciones de tamaño empresarial o de territorialidad.

Con la suscripción de varios tratados internacionales por parte de Colombia en materia de comercio en el periodo comprendido entre 2007 y 2019 que contienen capítulos de compras públicas, la Corte Constitucional desarrolló una línea que examina la constitucionalidad de dichas disposiciones en materia de contratación pública, por lo que se considera un segundo periodo de desarrollo de este tema. Es así como otra sentencia hito referente a la reciprocidad en materia de compras públicas fue la sentencia C-750 de 2008; con ocasión de la suscripción del acuerdo de promoción comercial entre Colombia y los Estados Unidos de América, la Corte Constitucional examinó la Ley 1143 de 2007, aprobatoria de dicho tratado. El capítulo 9 de dicho acuerdo estableció las reglas aplicables a la contratación pública. El artículo 9.2 se refiere a los principios generales, estableciendo el trato nacional y la no discriminación. El artículo 9.7 se refirió a las condiciones objetivas de participación.

La Corte Constitucional consideró que el capítulo nueve de este acuerdo resultaba compatible con el orden constitucional, por lo tanto, pasó a ser parte de la legislación contractual de las partes, ello debido a que se integró a las normas de contratación de la administración pública y los principios del debido proceso y la administración pública (arts. 29, 150, inc. final y 209 de la Constitución). Los principios generales de trato nacional y no discriminación se ajustan a la Constitución al propender por la apertura del mercado de contratación pública de bienes o servicios, otorgando participación a los proveedores extranjeros en condiciones de transparencia e igualdad.

En este sentido, las disposiciones del instrumento internacional no pueden interpretarse de forma aislada y no contextualizada, siendo este acuerdo compatible con los principios de la función pública que están al servicio de los intereses generales, entre estos, la 
igualdad, moralidad, eficacia, economía, celeridad, imparcialidad y publicidad, reconociendo además los principios de la reciprocidad de prestaciones, según el cual, lo importante y relevante en el régimen de contratación es la equivalencia real y objetiva entre los derechos y obligaciones que surgen de la relación contractual y el de la buena fe, que obliga a la Administración Pública y a los particulares contratistas a tener en cuenta las exigencias éticas que emergen de la mutua confianza en el proceso de celebración, ejecución y liquidación de los contratos. En suma, se declaró exequible la norma aprobatoria por considerar que cumplía con los principios de equidad y reciprocidad que fundamentan la integración comercial (arts. 9, 226 y 227 de la Constitución).

La sentencia C-031 de 2009 examinó la constitucionalidad de la Ley 1189 de 2008, aprobatoria del TLC entre Colombia y Chile. El capítulo 13 de dicho acuerdo estableció reglas aplicables a la contratación pública. Al igual que el tratado con Estados Unidos, el artículo 13.2 se refirió a los principios generales de trato nacional y no discriminación. De otra parte, el numeral $2^{\circ}$ del artículo 13.8 establece que las entidades estatales deben limitar las condiciones de participación en una contratación pública a la garantía del cumplimiento de capacidades legales, comerciales, técnicas y financieras evaluadas sobre la base de las actividades globales de negocio del oferente. La sección G, referente a notas generales, estableció que la reserva de contratos hasta por 125000 USD en beneficio de las micro, pequeñas y medianas empresas (mipymes), incluyendo cualquier tipo de preferencias, tales como el derecho exclusivo para proveer un bien o servicio; así como medidas conducentes a facilitar la desagregación tecnológica y la subcontratación.

Respecto a este acuerdo, la Corte Constitucional manifestó que se evidencia la conformidad del mismo con los postulados integracionistas constitucionales, por cuanto se liberaliza el comercio de 
bienes y servicios mediante la supresión de barreras arancelarias y medidas de efecto equivalente, generando un clima propicio para las inversiones recíprocas, fomentando la generación de empleo en los sectores exportadores. De igual forma, señaló que el capítulo de contratación pública busca lograr la apertura de los mercados de adquisición de bienes y servicios de las entidades públicas, en condiciones de igualdad y en un marco de transparencia, estableciendo cláusulas convencionales encaminadas a asegurar un trato nacional y no discriminatorio para los proveedores de bienes y servicios originarios de Chile y Colombia. Estas previsiones se ajustan a los principios que orientan la contratación pública en Colombia y que son igualmente conformes con lo dispuesto en el artículo 209 superior, en materia de principios rectores de la función administrativa.

Debe resaltarse que en Colombia se adoptó como modelo el caso chileno de contratación pública electrónica, denominado "ChileCompra”, materializado de forma similar a través de la plataforma SECOP y administrado por la Agencia Nacional de Contratación, Colombia Compra Eficiente, así como herramientas de e-Procure$m e n t^{26}$.

De otra parte, esta jurisprudencia mencionó para el presente caso el principio de "confianza legítima", consistente en que el particular debe poder evolucionar en un medio jurídico estable y previsible, en el cual pueda confiar. Las autoridades públicas tienen la obligación de preservar un comportamiento consecuente, no contradictorio frente a los particulares, surgido en un acto o acciones anteriores, incluso ilegales, salvo interés público imperioso contrario. Es una protección frente a cambios inesperados efectuados por las autoridades públicas.

26 Para $\mathrm{m}$ \{as información sobre e-Procurement puede consultarse el siguiente enlace: https:// publicadministration.un.org/publications/content/PDFs/E-Library\%20Archives/2011\%20 EGM Towards\%20Transparency\%20and\%20Efficiency\%20in\%20Public\%20Service.pdf 
La Corte Constitucional concluyó que no tiene reproche alguno de constitucionalidad respecto a este tratado, por cuanto los objetivos fijados coinciden con aquellos plasmados en los artículos 9, 226 y 227 de la carta política. De igual manera, se estableció como objetivo del TLC, entre otros, la promoción, en condiciones de equidad, del desarrollo equilibrado y armónico de las partes.

La sentencia C-446 de 2009 examinó la constitucionalidad de la Ley 1241 de 2008, aprobatoria del TLC entre Colombia, El Salvador, Guatemala y Honduras (Triángulo Norte Centroamérica). El capítulo 11 de dicho acuerdo estableció reglas aplicables a la contratación pública y el artículo 11.2 se refirió al trato nacional, no discriminación y transparencia. De esta forma, se ordenó que las partes apliquen sus procedimientos de contratación de forma que permitan la máxima competencia posible y respeten los principios de transparencia, publicidad y no discriminación.

En esta jurisprudencia, la Corte Constitucional manifestó que, en relación con el principio de pacta sunt servanda, las normas de derecho interno deben interpretarse de manera que armonicen con las obligaciones internacionales del Estado. Respecto al trato nacional, se entiende que las mercancías elaboradas en uno de los países que participan en este acuerdo deben ser tratadas en las mismas condiciones que se aplican a las mercancías nacionales en cada Estado, salvo las restricciones consagradas en el acuerdo.

De acuerdo con el análisis efectuado por la corporación, las normas en materia de contratación pública se ajustan a la Carta política porque desarrollan los principios de la función pública al servicio del interés general, como la igualdad, moralidad, eficacia, economía, celeridad, imparcialidad y publicidad. Estas reconocen el derecho interno de los Estados (Ley 80 de 1993 y demás normas reglamentarias) como aplicable en materia de contratación pública, promoviendo a la vez la integración comercial entre las partes. Tales disposiciones son 
exequibles por desarrollar los artículos 9, 13, 100, 226 y 227 de la Constitución. De esta jurisprudencia, se destaca que en el derecho internacional económico se ha examinado cómo la contratación estatal puede generar obstáculos no arancelarios cuando termina por discriminar a los productores y oferentes extranjeros, en relación con los proveedores nacionales.

La sentencia C-608 de 2010 examinó la constitucionalidad de la Ley 1363 de 2009, aprobatoria del TLC entre Canadá y Colombia. El capítulo 14 de dicho acuerdo estableció reglas aplicables a la contratación pública, el artículo 1403 fijó los principios generales de trato nacional y no discriminación y el artículo 1406, referente a las condiciones de participación y requisitos generales señaló que las entidades contratantes deben limitar las condiciones para participar en una contratación pública a aquellas que sean esenciales. Esto, con el fin de asegurarse de que el proveedor tiene la capacidad legal y solvencia financiera, así como la capacidad comercial y técnica para hacerse cargo de la contratación pública de que se trate. Este es un desarrollo del principio de selección objetiva que no permite la aplicación de criterios que lo desconozcan.

Tal jurisprudencia reiteró que el principio del trato nacional está dirigido a colocar en condiciones de igualdad jurídica a extranjeros y nacionales mientras que las cláusulas de la nación más favorecida tienen por objeto establecer y mantener en todo tiempo la igualdad fundamental, sin discriminación entre todos los países interesados. La corporación manifestó que en derecho internacional económico se examina hasta qué punto la contratación estatal puede generar obstáculos no arancelarios cuando termina por discriminar a los productores y oferentes extranjeros, en relación con los proveedores nacionales.

Según las disposiciones de la OMC, la existencia de los monopolios no genera obstáculos al comercio internacional, a menos que den preferencia a la comercialización de mercancías nacionales. La 
Corte Constitucional concluyó que el objetivo principal del capítulo 14 del acuerdo consiste en remover obstáculos existentes en ambos países en materia de contratación estatal, con base en la aplicación del principio de trato nacional y no discriminación. Por lo anterior, la Corte encontró estas previsiones ajustadas a los principios de la contratación pública y de la función administrativa.

La sentencia C-941 de 2010 examinó la constitucionalidad de la Ley 1372 de 2010, aprobatoria del TLC entre Colombia y los Estados de la Asociación Europea de Libre Comercio (AELC) (Suiza, Noruega, Islandia y Liechtenstein). El capítulo 7 de dicho acuerdo estableció reglas aplicables a la contratación pública. El artículo 7.4 se refirió a los principios generales de trato nacional y no discriminación. El artículo 7.7 del acuerdo, referente a las condiciones de participación, señaló que las entidades contratantes deben limitar tales condiciones a aquellas que sean esenciales para asegurar que un proveedor tenga las capacidades legales y financieras, y las habilidades comerciales y técnicas, para llevar a cabo la contratación relevante y evaluar las capacidades y habilidades sobre la base de las actividades comerciales del proveedor, tanto dentro como fuera del territorio de la parte de la entidad contratante.

Respecto a la participación de las pequeñas y medianas empresas (pymes), el artículo 7.19 del acuerdo indicó que las partes concuerdan en que es importante la participación de estas organizaciones en la contratación pública. Las partes reconocen la importancia de las alianzas empresariales entre los proveedores de cada parte, $y$ en particular de las pymes, por lo que acuerdan trabajar de forma conjunta con miras al intercambio de información y la facilitación del acceso de las pymes a los procedimientos, métodos y requisitos de la contratación pública, enfocados en las necesidades especiales de las pymes. De esta forma, se busca estimular la participación de estas empresas sin restringir o limitar la participación de oferentes extranjeros en los procesos de selección. 
En esta jurisprudencia, la Corte Constitucional señaló que los artículos 226 y 227 de la Constitución Política le imponen al Estado la promoción de la internacionalización de las relaciones económicas, sociales, políticas y ecológicas sobre bases de equidad, reciprocidad y conveniencia nacional. De igual forma incluyen la integración económica, social y política con las demás naciones, particularmente con los países de América Latina y del Caribe, mediante tratados sobre bases de equidad, igualdad y reciprocidad. Adicionalmente, se instituyó en el artículo 9 que las relaciones exteriores del Estado han de fundamentarse en el reconocimiento de los principios del derecho internacional aceptados por Colombia.

La Corte manifestó que, en el actual panorama de la globalización, la celebración de acuerdos de liberación comercial tiene por objetivo garantizar la competitividad de los países miembros, el desarrollo y crecimiento de las economías y, particularmente, el bienestar general de los pueblos, dentro de un ámbito de respeto por los valores, principios y derechos constitucionales. Respecto al capítulo de contratación pública de bienes y servicios, consideró que armoniza con la carta política, toda vez que amplía su marco al otorgar participación a los Estados de la AELC, bajo un ámbito jurídico preestablecido por las partes y sujeto a los principios que guían la función administrativa. En consecuencia, dicho capítulo fue declarado exequible por la Corte por atender los principios de equidad y reciprocidad que fundamentan la integración comercial (arts. 9, 226 y 227 superiores).

La sentencia C-335 de 2014 estudió la constitucionalidad de la Ley 1669 de 2013, aprobatoria del acuerdo comercial entre Colombia y el Perú, por una parte, y la Unión Europea (UE) y sus Estados miembros. El título VI de dicho acuerdo fijó reglas aplicables a la contratación pública. El artículo 174 estableció que las medidas adoptadas en materia de contratación estatal no podían constituir un medio de discriminación arbitraria o injustificable entre las partes o 
una restricción al comercio internacional. El artículo 175, referente a los principios generales, señaló que la UE y sus entidades contratantes otorgan inmediata e incondicionalmente a las mercancías y servicios de los países andinos signatarios y a sus proveedores, que ofrezcan tales mercancías y servicios, un trato no menos favorable que el trato otorgado a sus propios mercancías, servicios y proveedores.

Igualmente, cada país andino signatario y sus entidades contratantes otorgarán inmediata e incondicionalmente a las mercancías y servicios de la UE y a los proveedores de la UE, que ofrezcan tales mercancías y servicios, un trato no menos favorable que el trato otorgado a sus propios mercancías, servicios y proveedores. De otra parte, se prohíbe a las partes dar a un proveedor establecido en su territorio un trato menos favorable que el otorgado a otro instaurado en dicho territorio, en razón del grado de afiliación o propiedad extranjera; o discriminar a un proveedor establecido en su territorio en razón de que las mercancías o servicios ofrecidos por dicho proveedor para una determinada contratación pública sean mercancías o servicios de otra parte.

Por otra parte, el artículo 178, referente a las condiciones de participación, estableció que las entidades contratantes deben limitar las condiciones de participación en una contratación pública a aquellas que sean esenciales para asegurarse de que el proveedor tiene las capacidades jurídica, financiera, comercial y técnica para hacerse cargo de la contratación pública de que se trate. Para este fin, la entidad contratante verificará la capacidad financiera, comercial y técnica del proveedor sobre la base de sus actividades comerciales, tanto dentro como fuera del territorio de la parte de la entidad contratante, y que el proveedor tenga experiencia previa en el territorio de una parte.

Respecto a las mipymes, el artículo 192 estableció que las partes reconocen la importancia de su participación en la contratación 
pública, así como de las alianzas empresariales entre proveedores de las partes, y en particular de las mipymes. Las partes acuerdan intercambiar información y trabajar de manera conjunta con la finalidad de facilitar el acceso de las mipymes a los procedimientos, métodos y requisitos contractuales de la contratación pública, enfocándose en sus necesidades especiales.

La Corte Constitucional consideró que el mencionado capítulo se encuentra conforme al propósito general de asegurar que, en procedimientos de selección públicos, tanto los oferentes nacionales, como los extranjeros tengan la posibilidad de competir en condiciones de igualdad y con arreglo a principios de transparencia, publicidad, eficacia, no discriminación y con ceñimiento a las reglas del debido proceso.

Lo anterior, habida cuenta de los inconvenientes que suelen presentarse en derecho internacional económico cuando la contratación estatal puede genera obstáculos no arancelarios, discriminando a los productores y oferentes extranjeros, en relación con los proveedores nacionales. Por ello, en el ámbito internacional se pretende una apertura de la adquisición de bienes y servicios por las entidades públicas en condiciones de igualdad y con sujeción a un marco de transparencia, lo que no se opone al reconocimiento de las competencias estatales para regular la contratación administrativa. La corporación concluyó que el capítulo desarrolla los principios que guían la función administrativa, concediéndole relevancia al derecho nacional y expandiendo la integración comercial, llevando a sostener su constitucionalidad.

La sentencia C-620 de 2015 revisó la constitucionalidad de la Ley 1746 de 2014, aprobatoria del Protocolo Adicional del Acuerdo Marco de la Alianza del Pacífico (integrada por Chile, México, Perú y Colombia). El capítulo 8 de dicho acuerdo instauró las reglas aplicables a la contratación pública. El artículo 8.3, referente a los prin- 
cipios generales, estableció los de trato nacional y no discriminación. El artículo 8.12 señaló las condiciones para participar, acogiéndose al principio de selección objetiva, limitándose las entidades contratantes a establecer reglas que permitieran determinar la capacidad legal, comercial, técnica y financiera para cumplir con los requisitos y requerimientos técnicos de la contratación pública y así evaluar lo pertinente. El artículo 8.20 prohibió a las partes adoptar medidas que constituyeran un medio de discriminación arbitrario o injustificable.

El artículo 8.21, referente a la facilitación de la participación de las mipymes, estableció que las partes reconocían la contribución que se hace al crecimiento económico y al empleo, así como de las alianzas empresariales entre proveedores de las partes y las mipymes, por lo cual es relevante facilitar su participación en la contratación pública. Este artículo prevé que, cuando existan eventos en los que se otorgue un trato preferencial a las mipymes, se pueden hacer esfuerzos para reducir tales medidas o, en su defecto, asegurar que esas medidas, incluidos los criterios de elegibilidad, sean objetivas y transparentes.

Se destaca en esta sentencia el análisis que hizo la Corte respecto a la participación de las mipymes en la contratación pública. Precisa esta corporación que todos los interesados tienen el derecho a ubicarse en igualdad de condiciones para acceder a la contratación administrativa, gozando de las mismas oportunidades para participar en procesos de selección de contratistas. Asimismo, se puede exigir a las entidades contratantes que los pliegos de condiciones o sus equivalentes para la escogencia de los contratistas y las normas de selección se diseñen de manera que logren la igualdad entre los proponentes. Las entidades deben ceñirse al deber de selección objetiva del contratista, imponiendo una evaluación entre iguales y la escogencia del mejor candidato o proponente. Sin embargo, la Corte manifestó que está permitido el diseño de formas jurídicas transitorias dirigidas a favorecer a grupos sociales tradicionalmente discriminados o a 
privilegiar sujetos de especial protección constitucional, puesto que la filosofía humanista de la Constitución y la consagración del Estado social de derecho conciben la contratación administrativa como uno de los instrumentos adecuados para concretar y hacer efectivos los derechos de las personas, dirigido a servir a la comunidad, a promover la prosperidad general y a garantizar la materialización de los demás fines del Estado (preámbulo y artículos 1 y 2 de la Carta). Entre las mipymes debe existir un tratamiento igualitario.

Sobre el incentivo de la participación de mipymes en el mercado de las compras gubernamentales, considera la Corte que las políticas de falla de mercado u horizontales son de largo plazo y pretenden la disminución o eliminación de las barreras legales, administrativas, burocráticas (entre otras). De acuerdo con esto, pueden emplearse otras medidas, como el acceso de las mipymes a la información sobre las demandas, en términos de bienes y servicios de las entidades contratantes; capacitaciones sobre la normatividad y los procedimientos contractuales; el denominado ordering consistente en un crédito para prefinanciar las inversiones de capital de trabajo que se requieren para la ejecución, y el confirming permite a los contratistas liquidar sus facturas ante las entidades financieras, antes del vencimiento, mejorando su liquidez.

Por lo anterior, la Corte señaló que no son claras las reglas en materia de reciprocidad sobre este aspecto, por lo que no existe certeza sobre la forma en que se van a armonizar las obligaciones internacionales contenidas en el acuerdo y las constitucionales en materia de formulación de políticas públicas de fomento, promoción y competitividad de las pymes. Esto, en especial cuando existe el deber de suprimir el trato, diferenciando a las pymes colombianas en relación con sus similares extranjeras.

Por último, la Corte concluyó en esta sentencia que las disposiciones sobre contratación pública del acuerdo se encuentran acordes 
al ordenamiento jurídico constitucional, comprometiendo específicas áreas de integración económica o comercial. La corporación manifestó que este acuerdo propende por una competencia en condiciones de igualdad, promoviendo el comercio y la integración económica sobre las bases de equidad y reciprocidad, respetando las reglas del debido proceso, con sujeción a los principios de transparencia, publicidad y eficacia, y permitiendo afirmar la validez constitucional de este instrumento internacional (arts. 9, 29, 100, 209, 226 y 227 C. Pol.).

La sentencia C-157 de 2016 examinó la constitucionalidad de la Ley 1763 de 2015, aprobatoria del TLC entre Colombia y Costa Rica. El capítulo 10 de dicho acuerdo estableció reglas aplicables a la contratación pública. El artículo 10.2 prohibió a las partes adoptar medidas que constituyeran un medio de discriminación arbitraria o injustificable en materia de contratación pública. El artículo 10.3, referente a los principios generales, estableció los de trato nacional y no discriminación. El artículo 10.7, referente a condiciones de participación, obligó a las entidades a establecer reglas que permitieran asegurar que el oferente tuviera las capacidades legales y financieras y las habilidades comerciales y técnicas para cumplir con los requisitos y especificaciones técnicas objeto de contratación, sin importar su lugar de origen. El artículo 10.21 está relacionado con la participación de las mipymes y de las alianzas empresariales integradas por estas, por lo que las partes reconocen su importancia en la contratación pública.

En esta sentencia la Corte se ocupó del principio de reciprocidad, haciendo alusión a la correspondencia que debe existir entre un Estado y otro, en el curso de las relaciones internacionales. Sobre el particular, la Constitución acoge este principio sin realizar ninguna distinción entre sus formas. Por esta razón, el principio general del derecho que se debe seguir en la aplicación de la reciprocidad por parte de esta Corte no se debe limitar a una verificación de tratados internacionales, sino 
que debe igualmente abarcar un análisis de existencia de reciprocidad legislativa, con el fin de lograr iguales condiciones entre nacionales y extranjeros de los distintos Estados. Respecto al capítulo de contratación pública, la corporación consideró que se ajustaba a la Constitución al propender por la apertura del mercado de contratación pública de bienes o servicios otorgando participación a los proveedores extranjeros.

La correspondencia de estas cláusulas con la Carta deriva de la pluralidad de oferentes generando la satisfacción de las necesidades administrativas. En efecto, están justificadas las disposiciones especiales para la actividad de contratación de los Estados, pues responden a la importancia que tienen como actores del comercio, determinada, principalmente, por su condición de demandantes de altos volúmenes de bienes y servicios. Dichas disposiciones están dirigidas a la actividad y a los destinatarios de ese ejercicio de contratación, que obligan a que los compromisos en esa materia no afecten la soberanía (art. 9 CP) ni limiten el cumplimiento de los fines esenciales a su cargo, por lo tanto, se declara exequible el capítulo de compras públicas.

La sentencia C-184 de 2016 estudió la constitucionalidad de la Ley 1747 de 2014, aprobatoria del TLC entre Colombia y Corea. El capítulo 14 de dicho acuerdo estableció las reglas aplicables a las compras públicas. El artículo 14.2 prohibió a las partes adoptar, en materia de contratación pública, medidas de discriminación arbitrarias o injustificables. El artículo 14.3, referente a los principios generales, estableció los de trato nacional y no discriminación. El artículo 14.6, relacionado con las condiciones de participación, ordenó a las entidades contratantes a establecer requisitos objetivos que permitieran asegurar que el proveedor tuviera la capacidad jurídica, comercial, técnica y financiera para ejecutar el contrato derivado del proceso de selección, desarrollando el principio de selección objetiva. El artículo 14.16, referente a la participación de las mipymes, señaló 
la importancia de estas organizaciones empresariales y de sus alianzas con proveedores en la contratación pública, por lo que comprometió a las partes a intercambiar información y facilitar su acceso a los procedimientos de contratación.

En esta sentencia, la Corte Constitucional manifestó que las medidas que ha adoptado Colombia en el marco de TLC abren campo a los oferentes de otros países, propiciando un trato igualitario, no solo en la instancia de selección, sino en todas las etapas de la contratación que adelanta el Estado, lo que incluye la eliminación de requisitos marcados por la nacionalidad. Para la Corte, el capítulo de contratación pública se ajusta a la Constitución al propender por la apertura del mercado de contratación pública de bienes o servicios otorgando participación a los proveedores extranjeros. De igual forma, al facilitar la pluralidad de oferentes, se cumple con los cometidos del Estado al satisfacer las necesidades administrativas. La corporación encuentra justificadas las disposiciones especiales para la actividad de contratación de los Estados, quienes tienen la calidad de actores del comercio, por su alta demanda de bienes y servicios. Por ello, se declaró exequible el capítulo estudiado.

El análisis más reciente por parte de la Corte Constitucional en materia de compras públicas en TLC se realiza en la sentencia C-254 de 2019, que examinó la constitucionalidad de la Ley 1841 de 2017, aprobatoria del TLC entre Colombia y el Estado de Israel. El capítulo 9 de dicho acuerdo estableció las reglas aplicables a las compras públicas. El artículo 9.3 prohibió a las partes adoptar medidas que pudieran considerarse discriminatorias, arbitrarias o injustificables en materia de compras públicas. El artículo 9.4, referente a los principios generales, estableció los de trato nacional y no discriminación.

Por último, el artículo 9.7, relacionado con las condiciones de participación, ordenó a las partes ceñirse solo a criterios que permitieran comprobar la capacidad jurídica, comercial, financiera y 
técnica, sin importar el origen; ello, a efectos de garantizar la adecuada ejecución del contrato objeto del proceso de selección, desarrollando así el principio de selección objetiva. El artículo 9.19, referente a la participación de las mipymes, señaló la importancia de estas organizaciones empresariales y sus alianzas con proveedores en la contratación pública por lo que compromete a las partes a intercambiar información y facilitar su acceso a los procedimientos de contratación.

En esta jurisprudencia, la Corte analizó el fenómeno de la globalización económica, indicando que las fronteras internacionales han perdido relevancia en razón a los avances en las tecnologías de la información y de transporte, así como la introducción de políticas económicas abiertas en la mayoría de los países. El derecho internacional económico interactúa con otros sistemas normativos y, en términos generales, con el derecho internacional público, por lo cual resulta aplicable en la celebración de tratados comerciales. Por otro lado, manifestó que el proteccionismo económico incita a los países a replegarse sobre sí mismos, ignorando los flujos y reflujos del comercio internacional, aislándolos de la sociedad internacional. Es por ello que la internacionalización de las relaciones económicas se convierte en un hecho necesario para la supervivencia y el desarrollo de los Estados que trasciende las ideologías y los programas políticos. La existencia de medidas de apoyo interno puede distorsionar el comercio y afectar la producción.

La Corte declaró que los artículos sobre contratación pública resultan ajustados a la Constitución, toda vez que estas cláusulas propenden por la contratación en condiciones de igualdad, los principios generales y la participación de las mipymes. La finalidad de este capítulo es garantizar un marco regulatorio seguro para los proveedores participantes en el proceso de contratación pública, fundamentado en los principios de transparencia, trato nacional y no discriminación. 
En conclusión, este capítulo procura la apertura del mercado de contratación pública de mercancías y servicios concediendo participación a los proveedores extranjeros, además de establecer reglas y procedimientos que habrán de observar las empresas para el desarrollo de las actividades según el marco establecido. Por lo tanto, se cumplen los principios que iluminan la integración económica y comercial (equidad y reciprocidad) dentro del marco de la soberanía nacional y la autodeterminación de los pueblos, así como los principios de la función administrativa (arts. 9, 13, 29, 100, 209, 226, 227 y 333 superiores).

Una vez establecidas las disposiciones y compromisos adquiridos por Colombia en materia de contratación pública en TLC, es pertinente analizar su concordancia con lo establecido en el artículo 2 de la Ley 816 de 2003 y los artículos 2.2.1.2.4.2.2, 2.2.1.2.4.2.3 y 2.2.1.2.4.2.4 del Decreto 1082 de 2015.

Se puede evidenciar que ninguno de los capítulos de compras públicas estableció criterios de calificación por apoyo a la industria nacional o lineamientos generales para favorecer una oferta en virtud de su nacionalidad. Todos los acuerdos incluyen los principios de trato nacional y no discriminatorio en razón a la nacionalidad. En este sentido, con la aplicación de los criterios diferenciadores de calificación en los procesos de selección adelantados por entidades públicas colombianas se limita la reciprocidad. El artículo 2 de la Ley 816 de 2003 es de obligatoria observancia para todos los procesos, sin distinción alguna; por ello, al existir un mandato general, no se permite su modulación o atenuación en estas convocatorias. De igual forma, esta norma impone un criterio de desempate de preferencia a la oferta nacional, que claramente va en contravía de los compromisos asumidos por el Estado colombiano en estos tratados internacionales.

Respecto a las mipymes, si bien en diversos tratados se reconoce su importancia en la contratación estatal, en concordancia 
con lo establecido en la Ley 590 de 2000 y la Ley 1150 de 2007. Debe precisarse que el mandato de estas normas, y los compromisos internacionales, es el de fomentar su participación en los procesos contractuales de la administración, no el de establecer criterios restrictivos o discriminatorios para la participación de proponentes extranjeros. Los capítulos de compras públicas no establecen la aceptación de convocatorias limitadas a mipymes (salvo el TLC con Estados Unidos) por lo que los artículos 2.2.1.2.4.2.2 y 2.2.1.2.4.2.4 del Decreto 1082 de 2015, referente a las convocatorias limitadas a mipymes, no se encuentran en concordancia con los compromisos adquiridos por Colombia con otros Estados.

En relación con las convocatorias limitadas territorialmente, contempladas en el artículo 2.2.1.2.4.2.3 del Decreto 1082 de 2015, se evidenció que los capítulos de compras públicas no establecían la aceptación de convocatorias limitadas territorialmente, por lo cual no puede alegarse el fomento de la participación de las mipymes, establecido en estos tratados, para justificar tal medida discriminatoria de ofertas extranjeras. Por tal razón, se concluye igualmente que esta disposición no se encuentra en concordancia con los compromisos adquiridos por Colombia con otros Estados.

\section{Conclusiones}

Teniendo en cuenta que la presente investigación tuvo como objetivo general establecer si las disposiciones contenidas en el artículo 2 de la Ley 816 de 2003 y los artículos 2.2.1.2.4.2.2, 2.2.1.2.4.2.3 y 2.2.1.2.4.2.4 del Decreto 1082 de 2015, referentes a convocatorias limitadas a mipymes y limitaciones territoriales, contravienen lo establecido en los artículos 226 y 227 de la Constitución Política de 1991, así como el artículo 20 de la Ley 80 de 1993, la pregunta se resuelve de manera positiva; la hipótesis planteada se acepta en razón a lo siguiente: 
La reciprocidad consiste en otorgar un trato semejante al que se recibe por parte de otro sujeto de derecho internacional sin ejercer actos discriminatorios. Este trato de igual forma debe ser observado por sus administrados. Este principio fue incluido en la Constitución Política de 1991 en los artículos 226 y 227 y se extiende también a la contratación pública en Colombia a través del artículo 20 de la Ley 80 de 1993.

Las Leyes 590 de 2000 y 1150 de 2007 contemplan una política de formación y crecimiento de las mipymes utilizando como herramienta la contratación pública sin establecer de forma expresa criterios diferenciadores entre ofertas nacionales y extranjeras. Sin embargo, la Ley 816 de 2003 y el Decreto 1082 de 2015, bajo el concepto de apoyo a la industria nacional e incentivos, establecen criterios diferenciadores al momento de dar apertura a una convocatoria y evaluar respecto a las ofertas nacionales y extranjeras en procesos contractuales adelantados por entidades públicas en Colombia.

De acuerdo con los lineamientos constitucionales y los tratados de cooperación suscritos por Colombia con miras a la integración regional, el principio de reciprocidad en materia de contratación no debería encontrar obstáculo alguno para su desarrollo en la legislación interna. Por ende, la regulación de los contratos públicos ya no obedece exclusivamente a una política interna sino a los compromisos adquiridos en materia internacional. Aunque los TLC que contienen capítulos de compras públicas suscritos por Colombia no tienen una jerarquía superior a las leyes ordinarias, han sido aprobados por una ley que, a su vez, ha sido examinada por la Corte Constitucional, por lo cual es de obligatorio cumplimiento para el Estado.

La fuerza vinculante de estos acuerdos impone a los signatarios la armonización de sus disposiciones con la legislación interna. En este sentido, los principios generales de trato nacional y no discriminación incluidos deben aplicarse sin limitaciones en los procesos 
contractuales públicos. Actualmente, ni el poder legislativo ni el ejecutivo han tenido en cuenta la realidad sobre los compromisos adquiridos en el marco de acuerdos internacionales que tienen una aplicación directa sobre el derecho contractual público interno.

Una vez examinados los compromisos establecidos en los capítulos de compras públicas de TLC suscritos por Colombia, se puede evidenciar que ninguno de estos establece criterios de calificación por apoyo a la industria nacional o establece lineamientos generales para favorecer una oferta en virtud de su nacionalidad. Todos los acuerdos incluyen los principios de trato nacional y no discriminatorio en razón a la nacionalidad. En este sentido, con la aplicación de los criterios diferenciadores de calificación en los procesos de selección adelantados por entidades públicas colombianas, se limita la reciprocidad. Al ser de obligatorio cumplimiento la aplicación del artículo $2^{\circ}$ de la Ley 816 de 2003 para las entidades estatales en todos sus procesos contractuales, se imponen medidas discriminatorias que claramente van en contravía con los compromisos asumidos por el Estado colombiano en tratados internacionales.

Respecto a las mipymes, en diversos tratados se reconoce su importancia en la contratación estatal, en concordancia con lo establecido la Ley 590 de 2000 y la Ley 1150 de 2007. Sin embargo, los artículos 2.2.1.2.4.2.2, 2.2.1.2.4.2.3 y 2.2.1.2.4.2.4 del Decreto 1082 de 2015 establecen criterios restrictivos y discriminatorios de ofertas extranjeras, toda vez que los capítulos de compras públicas de TLC no establecen la aceptación de convocatorias limitadas a mipymes (salvo el TLC con Estados Unidos) o de convocatorias limitadas territorialmente. Por lo anterior, igualmente se concluye que estas disposiciones no se encuentran en concordancia con los compromisos adquiridos por Colombia con otros Estados.

Con la implementación de estas medidas, en la práctica no se evidencia el cumplimiento de los cometidos de la Ley 816 de 2003 y 
el Decreto 1082 de 2015. Esto debido a que los porcentajes de calificación de apoyo a la industria nacional, las convocatorias limitadas a mipymes o delimitadas territorialmente son incluidas en los pliegos de condiciones de diferentes procesos contractuales simplemente para cumplir con un requisito obligatorio y no con la finalidad de obtener mejores ofertas locales que cumplan con las condiciones jurídicas, financieras, económicas y técnicas que permitan seleccionar la mejor oferta para la entidad contratante. De esta forma, se otorga una ventaja injustificada a la oferta nacional y no se garantiza la idoneidad del contratista seleccionado que pueda ejecutar el contrato derivado del proceso de selección en las mejores condiciones. Es así como se limitan los principios de selección objetiva, igualdad y principalmente, el de reciprocidad.

Por lo esgrimido en párrafos anteriores, el presente documento cumplió con el objetivo general y los objetivos específicos planteados, demostrando de forma positiva la hipótesis al delimitar conceptualmente el principio de reciprocidad y sus limitaciones en la contratación estatal en Colombia, y efectuar el análisis del desarrollo jurisprudencial por parte de la Corte Constitucional en el examen de tratados de libre comercio que contienen capítulos de compras públicas.

\section{Referencias bibliográficas}

Asamblea Nacional Constituyente. (1991). Constitución Política de Colombia. Gaceta Constitucional No. 116 de 20 de julio de 1991. Bogotá D.C., Colombia.

Benavides, J. (2014). Contratos públicos. Estudios. Universidad Externado de Colombia.

Campanelli, M. (2019). El derecho administrativo tradicional en el Estado postmoderno: globalización, buena administración y supranacionalidad. (El caso OCDE-Colombia). Revista Digital de Derecho Administrativo, (21), 201-219. https://revistas.uexternado.edu.co/index.php/Deradm/article/view/5705/7101

Cassese, S. (2005). Administrative law without the state - The challenge of global regulation. University Journal of International Law and Politics, 37(4), 663-694. https://www.illi.org/ publications/administrative-law-without-the-state-the-challenge-of-global-regulation 
Comisión de Derecho internacional de las Naciones Unidas [CDI] (1961). Convención de Viena sobre relaciones diplomáticas de 18 de abril de 1961. ONU.

Comisión de Derecho Internacional de las Naciones Unidas [CDI] (1969). Convención de Viena sobre derecho de los tratados de 23 de mayo de 1969. ONU.

Congreso de la República de Colombia. (1972). Ley 6 del 15 de noviembre de 1972. Diario Oficial No. 33.750 [Por la cual se aprueba la Convención de Viena sobre Relaciones Diplomáticas hecha en Viena el 18 de abril de 1961]. http://www.suin-juriscol.gov.co/ viewDocument.asp?ruta $=$ Leyes $/ 1561543$

Congreso de la República de Colombia. (1973). Ley 8 del 14 de abril de 1973. Diario Oficial No. 33.853 [Por la cual se aprueba un convenio internacional y se determinan las modalidades de su aplicación]. http://www.suin-juriscol.gov.co/viewDocument. asp?ruta $=$ Leyes $/ 1563767$

Congreso de la República de Colombia. (1981). Ley 45 del 6 de mayo de 1981. Diario Oficial No. 35.776 [Por medio de la cual se aprueba el Tratado de Montevideo 1980, firmado en Montevideo el 12 de agosto de 1980]. http://www.suin-juriscol.gov.co/viewDocument.asp?ruta $=$ Leyes $/ 1600019$

Congreso de la República de Colombia. (1985). Ley 32 del 29 de enero de 1985. Diario Oficial No. 36.856 [Por medio de la cual se aprueba la Convención de Viena sobre el Derecho de los Tratados, suscrita en Viena el 23 de mayo de 1969]. https://www. mintic.gov.co/portal/604/articles-3718 documento.pdf

Congreso de la República de Colombia. (1993). Ley 80 del 28 de octubre de 1993. Diario Oficial No. 41.094 [Por la cual se expide el Estatuto General de Contratación de la Administración Pública]. http://www.secretariasenado.gov.co/senado/basedoc/ley 0080 1993.html

Congreso de la República de Colombia. (1994). Ley 172 del 20 de diciembre de 1994. Diario Oficial No. 41.671 [Por medio de la cual se aprueba el Tratado de Libre Comercio entre los Gobiernos de Estados Unidos Mexicanos, la República de Colombia y la República de Venezuela, suscrito en Cartagena de Indias el 13 de junio de 1994]. http:// www.secretariasenado.gov.co/senado/basedoc/ley_0172_1994.html

Congreso de la República de Colombia. (2000). Ley 590 del 10 de julio de 2000. Diario Oficial No. 44.078 [Por la cual se dictan disposiciones para promover el desarrollo de las micro, pequeñas y medianas empresa]. http://www.secretariasenado.gov.co/ senado/basedoc/ley_0590_2000.html

Congreso de la República de Colombia. (2003). Ley 816 del 7 de julio de 2003. Diario Oficial No. 45.242 [Por medio de la cual se apoya a la industria nacional a través 
de la contratación pública]. http://www.secretariasenado.gov.co/senado/basedoc/ ley_0816_2003.html

Congreso de la República de Colombia. (2007). Ley 1150 del 16 de julio de 2007. Diario Oficial No. 46.691 [Por medio de la cual se introducen medidas para la eficiencia y la transparencia en la Ley 80 de 1993 y se dictan otras disposiciones generales sobre la contratación con Recursos Públicos]. http://www.secretariasenado.gov.co/senado/ basedoc/ley 1150 2007.html

Congreso de la República de Colombia. (2007). Ley 1143 del 4 de julio de 2007. Diario Oficial No. 46.679 [Por medio de la cual se aprueba el Acuerdo de promoción comercial entre la República de Colombia y los Estados Unidos de América, sus Cartas Adjuntas y sus Entendimientos, suscritos en Washington el 22 de noviembre de 2006]. http:// www.secretariasenado.gov.co/senado/basedoc/ley_1143_2007.html

Congreso de la República de Colombia. (2008). Ley 1189 del 28 de abril de 2008. Diario Oficial No. 46.974 [Por medio de la cual se aprueba el Acuerdo de Libre Comercio entre la República de Colombia y la República de Chile - Protocolo adicional al Acuerdo de Complementación Económica para el Establecimiento de un Espacio Económico Ampliado Entre Colombia y Chile (ACE 24) del 6 de diciembre de 1993, suscrito en Santiago, Chile, el 27 de noviembre de 2006.]. http://www.secretariasenado.gov.co/ senado/basedoc/ley_1189_2008.html

Congreso de la República de Colombia. (2008). Ley 1241 del 30 de julio de 2008. Diario Oficial No. 47.066 [Por medio de la cual se aprueba el Tratado de Libre Comercio entre la República de Colombia y las Repúblicas de El Salvador, Guatemala y Honduras, hecho y firmado en Medellín, República de Colombia, el 9 de agosto de 2007, y los Canjes de Notas que Corrigen el Anexo 3.4 del Capítulo III relativo al Trato Nacional y Acceso de Mercancías al Mercado. Sección Agrícola - Lista de Desgravación de Colombia para El Salvador, Guatemala y Honduras, del 16 de enero de 2008, 11 de enero de 2008 y 15 de enero de 2008, respectivamente]. http://www.secretariasenado.gov.co/ senado/basedoc/ley_1241_2008.html

Congreso de la República de Colombia. (2009). Ley 1363 del 9 de diciembre de 2009. Diario Oficial No. 47.558 [Por medio de la cual se aprueba el Acuerdo de Libre Comercio entre Canadá y la República de Colombia, hecho en Lima, Perú, el 21 de noviembre de 2008, y el Canje de notas entre Canadá y la República de Colombia del 20 de febrero de 2009, por medio del cual se corrigen errores técnicos y materiales del Acuerdo de Libre Comercio entre Canadá y la República de Colombia]. http://www.secretariasenado.gov.co/senado/basedoc/ley 1363 2009.html

Congreso de la República de Colombia. (2010). Ley 1372 del 7 de enero de 2010. Diario Oficial No. 47.585 [Por medio de la cual se aprueba el Acuerdo de Libre Comercio 
entre la República de Colombia y los Estados AELC y el Canje de Notas respecto del Capítulo 4 del Acuerdo de Libre Comercio entre la República de Colombia y los Estados AELC, suscritos en Ginebra, a los 25 días del mes de noviembre de dos mil ocho; el Acuerdo sobre Agricultura entre la República de Colombia y la Confederación Suiza, hecho en Ginebra, a los 25 días del mes de noviembre de 2008; el Acuerdo sobre Agricultura entre la República de Colombia y la República de Islandia, hecho en Ginebra, a los 25 días del mes de noviembre de 2008; y el Acuerdo sobre Agricultura entre la República de Colombia y el Reino de Noruega, hecho en Ginebra, a los 25 días del mes de noviembre de 2008]. http://www.secretariasenado.gov.co/senado/ basedoc/ley_1372_2010.html

Congreso de la República de Colombia. (2013). Ley 1669 del 16 de julio de 2013. Diario Oficial No. 48.853 [Por medio de la cual se aprueba el Acuerdo Comercial entre Colombia y el Perú, por una parte, y la Unión Europea y sus Estados Miembros, por otra, firmado en Bruselas, Bélgica, el 26 de junio de 2012]. http://www.secretariasenado. gov.co/senado/basedoc/ley_1669_2013.html

Congreso de la República de Colombia. (2014). Ley 1746 del 26 de diciembre de 2014. Diario Oficial No. 49.376 [Por medio de la cual se aprueba el Protocolo adicional al Acuerdo Marco de la Alianza del Pacífico, firmado en Cartagena de Indias, República de Colombia, el 10 de febrero de 2014]. http://www.secretariasenado.gov.co/senado/ basedoc/ley_1746_2014.html

Congreso de la República de Colombia. (2014). Ley 1747 del 26 de diciembre de 2014. Diario Oficial No. 49.376 [Por medio de la cual se aprueba el Acuerdo de Libre Comercio entre la República de Colombia y la República de Corea, firmado en Seúl, República de Corea, el 21 de febrero de 2013]. http://www.secretariasenado.gov.co/senado/ basedoc/ley 1747 2014.html

Congreso de la República de Colombia. (2015). Ley 1763 del 15 de julio de 2015. Diario Oficial No. 49.574 [Por medio de la cual se aprueba el Tratado de Libre Comercio entre la República de Colombia y la República de Costa Rica, suscrito en Cali, República de Colombia, el 22 de mayo de 2013]. http://www.secretariasenado.gov.co/senado/ basedoc/ley 1763 2015.html

Congreso de la República de Colombia. (2017). Ley 1841 del 12 de julio de 2017. Diario Oficial No. 50.292 [Por medio de la cual se aprueba el Tratado de Libre Comercio entre la República de Colombia y el Estado de Israel, hecho en Jerusalén, Israel, el 30 de septiembre de 2013 y el Canje de Notas entre la República de Colombia y el Estado de Israel, por medio de la cual se corrigen errores técnicos del Tratado de Libre Comercio entre la República de Colombia y el Estado de Israel, efectuado el 13 de noviembre de 2015]. http://www.secretariasenado.gov.co/senado/basedoc/ley 1841_2017.html 
Conrado, R. (2012). Los principios en la contratación estatal: aspectos constitucionales legales y jurisprudenciales. Grupo Editorial Ibañez.

Corte Constitucional. Sala Plena de la Corte Constitucional. (25 de abril de 1995). Sentencia C-178/95. [M.P Fabio Morón Díaz]. https://www.corteconstitucional.gov.co/ relatoria/1995/C-178-95.htm

Corte Constitucional. Sala Plena de la Corte Constitucional. (24 de julio de 2008). Sentencia C-750/08. [M.P Clara Inés Vargas Hernández]. https://www.corteconstitucional.gov. co/relatoria/2008/C-750-08.htm

Corte Constitucional. Sala Plena de la Corte Constitucional. (28 de enero de 2009). Sentencia C-031/09. [M.P Humberto Antonio Sierra Porto]. https://www.corteconstitucional.gov.co/relatoria/2009/C-031-09.htm

Corte Constitucional. Sala Plena de la Corte Constitucional. (8 de julio de 2009). Sentencia C-446/09. [M.P Mauricio González Cuervo]. https://www.corteconstitucional.gov.co/ relatoria/2009/C-446-09.htm

Corte Constitucional. Sala Plena de la Corte Constitucional. (3 de agosto de 2010). Sentencia C-608/10. [M.P Humberto Antonio Sierra Porto]. https://www.corteconstitucional.gov.co/relatoria/2010/C-608-10.htm

Corte Constitucional. Sala Plena de la Corte Constitucional. (24 de noviembre de 2010). Sentencia C-941/10. [M.P Jorge Iván Palacio]. https://www.corteconstitucional.gov. co/relatoria/2010/C-941-10.htm

Corte Constitucional. Sala Plena de la Corte Constitucional. (4 de junio de 2014). Sentencia C-335/14. [M.P Gabriel Eduardo Mendoza Martelo]. https://www.corteconstitucional. gov.co/relatoria/2014/C-335-14.htm

Corte Constitucional. Sala Plena de la Corte Constitucional. (15 de abril de 2015). Sentencia C-163/15. [M.P Martha Victoria Sáchica Méndez]. https://www.corteconstitucional. gov.co/relatoria/2015/C-163-15.htm

Corte Constitucional. Sala Plena de la Corte Constitucional. (6 de abril de 2016). Sentencia C-157/16. [M.P Gloria Stella Ortiz Delgado]. https://www.corteconstitucional.gov.co/ relatoria/2016/C-157-16.htm

Corte Constitucional. Sala Plena de la Corte Constitucional. (14 de abril de 2016). Sentencia C-184/16. [M.P Gloria Stella Ortiz Delgado]. https://www.corteconstitucional.gov.co/ relatoria/2016/C-184-16.htm 
Corte Constitucional. Sala Plena de la Corte Constitucional. (6 de junio de 2019). Sentencia C-254/19. [M.P José Fernando Reyes Cuartas]. https://www.corteconstitucional.gov. co/relatoria/2019/C-254-19.htm

Dávila, L. (2016). Régimen jurídico de la contratación estatal. Legis.

Departamento Nacional de Planeación. (2015). Decreto 1082 del 26 de mayo de 2015. [Por medio del cual se expide el Decreto Único Reglamentario del sector administrativo de Planeación Nacional]. https://www.dnp.gov.co/Paginas/Normativa/Decreto1082-de-2015.aspx

Feler, A. (2015). Soft Law como herramienta de adecuación del Derecho Internacional a las nuevas coyunturas. Lecciones y Ensayos (95), 281-303. http://www.derecho.uba. ar/publicaciones/lye/revistas/95/soft-law-como-herramienta-de-adecuacion-delderecho-internacional-a-las-nuevas-coyunturas.pdf

Guinard-Hernández, D. (2017). La regulación económica como instrumento de intervención estatal en la economía. Revista digital de Derecho Administrativo, 18(2), 177-224. https://revistas.uexternado.edu.co/index.php/Deradm/article/view/5010/6110

Guzmán, A. (2003). La doctrina de la "Consideration" en Blackstone y sus relaciones con la "Causa" en el "lus Commune". Revista de estudios histórico-jurídicos. XXV, 375-406. http://www.rehj.cl/index.php/rehj/article/view/385/362

Hinojosa, L. (2010). La regulación jurídica del sistema económico internacional. En Hinojosa, L., \& Roldán, F. (coord.), Derecho internacional económico. (pp. 27-51). Marcial Pons.

Jiménez, J. (1988). Derecho Constitucional: sistema de fuentes. Revista española de Derecho Constitucional, 8(23) 305-322. https://dialnet.unirioja.es/descarga/articulo/2011884.pdf

Keohane, R. (1986). Reciprocity in International Relations. International Organization, 40 (1), 1-27. http://www.jstor.org/stable/2706740

Kingsbury, B., Krisch, N., \& Stewart, R. (marzo de 2010). El surgimiento del Derecho Administrativo Global. (Trad. Paris G., Ricart, L.). Revista de Derecho Público, 24, 1-46. https://derechopublico.uniandes.edu.co/components/com_revista/archivos/derechopub/pub87.pdf (Trabajo original publicado en 2005)

Mesa-Moles, M. (2007). Génesis y formación del Derecho Internacional Privado: una aproximación histórica. [Tesis Doctoral, Universidad Rey Juan Carlos]. https://eciencia. 
urjc.es/bitstream/handle/10115/1058/TESIS\%20MESA\%20MOLES.pdf;jsessionid=E 1CF6462FC803EF1FED5F6CAB3D3285F?sequence $=1$

Ministerio de Hacienda y Crédito Público. Ministerio de Comercio Industria y Turismo (1994). Decreto 2891 del 30 de diciembre de 1994. [Por el cual se da cumplimiento a compromisos contraídos por Colombia en el Marco de la Asociación Latinoamericana de Integración, Aladi]. http://www.suin-juriscol.gov.co/viewDocument. $\underline{\text { asp? } r u t a=\text { Decretos } / 1499118}$

Pastrana, E. (2005). El principio de la no-reciprocidad: entre el deber ser y su regulación jurídica en el marco de las relaciones económicas internacionales y de cooperación. Papel Político, 67-117. https://www.redalyc.org/articulo.0a?id=77720407003

Pardo, N. (2011). Los principios de igualdad y reciprocidad en ofertas extranjera vs. las mipymes en contratación estatal: un límite a la globalización. Saber, Ciencia y Libertad, 75-87. Obtenido de https://dialnet.unirioja.es/descarga/articulo/3997346.pdf

Ponce, J. (2010). Procedimiento administrativo, globalización y buena administración. En Ponce, J. (coord.), Derecho administrativo global: organización, procedimiento, control judicial. (pp. 79-190). Instituto Nacional de Administración Pública - INAP, Marcial Pons.

Prebisch, R. (1962). Reflexiones sobre la Integración Económica Latinoamericana. Revista de Economía y Estadística, Tercera Época. 6(1), 175-188. http://revistas.unc.edu.ar/ index.php/REyE/article/view/3506

Presidencia de la República de Colombia. (2015). Decreto 1082 del 26 de mayo de 2015 [Sector administrativo de planeación nacional]. Bogotá D.C., Colombia.

Rodríguez, L. (2016). El derecho administrativo transnacional o global: un nuevo capítulo del derecho administrativo. En Rodríguez, J. \& Hernández, J. (coord.), El derecho administrativo global y el arbitraje internacional de inversiones una perspectiva iberoamericana en el marco del cincuenta aniversario del CIADI. (pp. 57-93). Instituto Nacional de Administración Pública - INAP.

Rodríguez-Arana, J. (2011). Los principios del Derecho global de la contratación pública. Derecho PUCP, (66) 29-54. http://revistas.pucp.edu.pe/index.php/derechopucp/article/view/3146/3462

Rodríguez-Arana, J. (2016). El derecho administrativo global: el espacio jurídico-administrativo iberoamericano. En Rodríguez, J. \& Hernández, J. (coord.), El derecho administrativo global y el arbitraje internacional de inversiones una perspectiva iberoamericana en el marco del cincuenta aniversario del CIADI. (pp. 23-56). Instituto Nacional de Administración Pública - INAP. 
Rojas, V. (2011). Acuerdos de promoción comercial y contrataciones estatales: especial referencia a los límites de los poderes públicos en el espacio jurídico global. Derecho PUCP, (66), 301-318. http://revistas.pucp.edu.pe/index.php/derechopucp/article/ view/3377/3226

Ruffert, M. \& Steinecke, S. (2011). Global Administrative Law. En Ruffert, M. \& Steinecke, S. The Global Administrative Law of Science. (pp. 15-28). Springer-Verlag Berlin Heidelberg.

Shing-I, L. (2009). El principio de reciprocidad y la globalización del Derecho desde la perspectiva de la regla de oro. Persona y Derecho: Revista de Fundamentación de las Instituciones Jurídicas y de Derechos Humanos (60), 19-28. https://revistas.unav. edu/index.php/persona-y-derecho/article/view/31730/27019

Suárez, G. (2009). La nueva contratación pública en Colombia. Legis.

Wolters Kluwer. (s.f.). Wolters Kluwer. Obtenido de Reciprocidad: https://guiasjuridicas. wolterskluwer.es/Content/Documento.aspx? params $=\mathrm{H} 4$ sIAAAAA AAEAMtMSbF1jTAAAUMzA3MTtbLUouLM_DxbIwMDC0NDI10QQGZapUtckhlQaptWmJOcSoAIEBcnjUAAAA =WKE 
